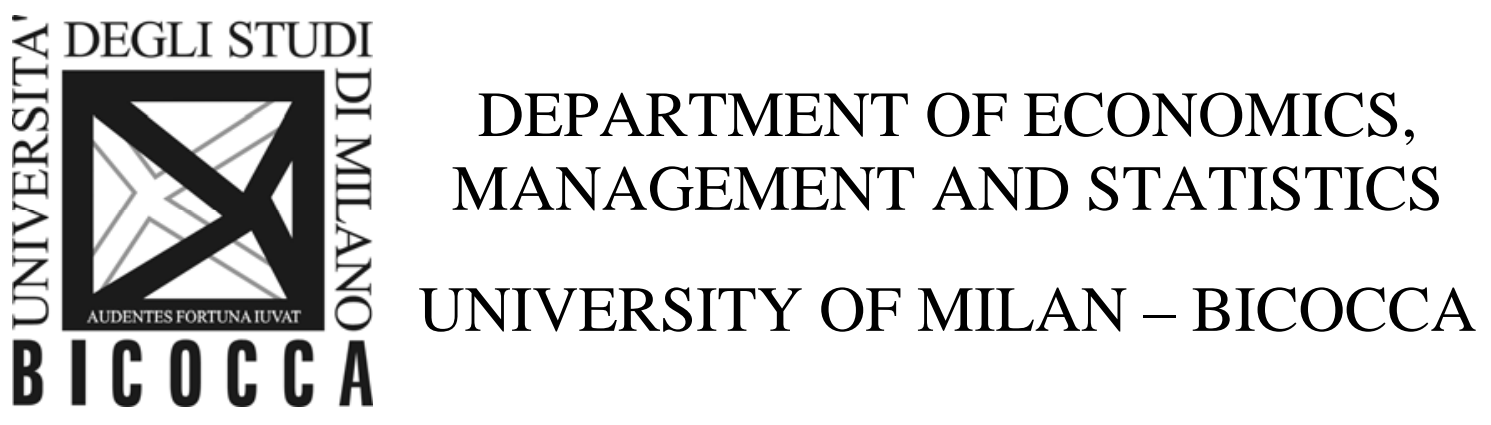

DEMS WORKING PAPER SERIES

\title{
Cognitive Ability and Games of School Choice
}

Christian Basteck, Marco Mantovani

No. 343 - June 2016

Dipartimento di Economia, Metodi Quantitativi e Strategie di Impresa Università degli Studi di Milano - Bicocca 


\title{
Cognitive Ability and Games of School Choice
}

\author{
Christian Basteck* $\quad$ Marco Mantovani ${ }^{\dagger}$ \\ June 2016
}

\begin{abstract}
We take school admission mechanisms to the lab to test whether the manipulable Boston mechanism disadvantages students of lower cognitive ability and whether this leads to ability segregation across schools. Results show this is the case: lower ability participants receive a lower average payoff and are over-represented at the worst school. Under the strategy-proof Deferred Acceptance mechanism, payoff differences between high and low ability participants are reduced, and distributions by ability across schools are harmonized. Hence, we find support for the argument that a move to strategy-proof mechanisms would "level the playing field". However, we document a trade-off between equality and efficiency in the choice of school admission mechanisms since average payoffs are larger under Boston than under Deferred Acceptance.
\end{abstract}

Keywords: laboratory experiment, school choice, strategy-proofness, cognitive ability, mechanism design.

JEL codes: C78, C91, D82, I24.

\footnotetext{
*Technische Universität Berlin. christian.basteck@tu-berlin. de

${ }^{\dagger}$ Department of economics, University of Milan Bicocca. marco.mantovani@unimib. it

Acknowledgements: the authors would like to thank Estelle Cantillon, Antonio Miralles, Daniela Grieco, Frank Heinemann, Yinghua He as well as participants to presentations in Alghero, Berlin, Brussels, Helsinki, London, Maastricht, Milan, and Toulouse for valuable comments and suggestions to improve the paper. Marco Mantovani is a postdoc researcher of the University of Milan-Bicocca. Support from UNU-WIDER under project 'Discrimination and Affirmative action: What have we learnt so far?' and from Deutsche Forschungsgemeinschaft through project SFB 649 is gratefully acknowledged.
} 


\section{Introduction}

The paper studies experimentally how different allocation mechanisms influence inequality, efficiency and ability segregation across schools. In particular, we consider the hypothesis that students of lower cognitive ability are less able to identify optimal strategies under the Boston mechanism, which lets them fare worse under this mechanism compared to peers of higher ability and results in ability segregation across schools.

Protecting applicants who do not strategize well is one of the main arguments of those who advocate in favor of strategy-proof mechanisms in school choice - e.g., Deferred Acceptance (DA) - and against manipulable ones - e.g., Boston (BOS). Pathak and Sönmez [2008] show that if some applicants report sincerely under BOS while others best respond, sincere applicants are disadvantaged in equilibrium; in contrast DA - where sincere reports are always optimal - levels the playing field for sincere applicants. ${ }^{1}$ Moreover, if the failure to strategize correlates with belonging to an already disadvantaged group, BOS would selectively discriminate against the weakest students. ${ }^{2}$

Whilst manipulable mechanisms are challenging for applicants, decisions whether and how to manipulate may reveal information on cardinal preferences [Abdulkadiroğlu et al., 2011; Miralles, 2009]. For example under BOS, only applicants with a particularly strong preference should apply at an overdemanded school, while applicants who are almost indifferent between overand under-demanded schools should apply at the latter. As a consequence, schools would be more likely to admit students that appreciate it more, which would increase welfare from a utilitarian perspective.

Our contribution is twofold. First, by matching cognitive ability and behavior in a school choice game, we are able to investigate whether DA levels the playing field between applicants of different ability. Second, we test whether students are sufficiently sophisticated for the welfare gains of BOS to arise. Hence, we offer a tentative estimate of the costs and benefits of mov-

\footnotetext{
${ }^{1}$ The mechanism design approach to school choice has highlighted the drawbacks of manipulable mechanisms from the very beginning. See the seminal paper by Abdulkadiroğlu and Sönmez [2003], and the characterization of equilibria under the Boston mechanism in [Ergin and Sönmez, 2006]. See also Roth and Sotomayor [1992] on the college admission problem.

${ }^{2}$ For instance, in his often-cited memo to the Boston School Committee on May 25, 2005, Superintendent Payzant wrote: "the need to strategize provides an advantage to families who have the time, resources and knowledge to conduct the necessary research" and "a strategyproof algorithm levels the playing field by diminishing the harm done to parents who do not strategize or do not strategize well".
} 
ing from BOS to DA. Since these hypotheses are hard to pin down in the field where preferences are unobservable, we employ laboratory experiments.

In our setup, we measure subjects' cognitive ability using a 36 questions, non-verbal Raven test, before letting them apply for a seat at one of four schools. ${ }^{3}$ Subjects play ten school choice games, always under the same mechanism - i.e., either BOS or DA - and under two different preference environments. Induced preferences and cognitive ability are uncorrelated and there is only one priority class at each school, ${ }^{4}$ so that, in equilibrium, the distribution of subjects by ability should be the same at every school. That is, ability segregation cannot emerge in the absence of systematic differences in strategic behavior.

Manipulation under BOS typically takes the form of moving up undersubscribed schools in the submitted rank-order list. For instance, the West Zone Parents Group in Boston advised parents [see, among others, Pathak and Sönmez, 2008]:

One school choice strategy is to find a school you like that is undersubscribed and put it as a top choice, OR, find a school that you like that is popular and put it as a first choice and find a school that is less popular for a safe second choice.

The first advised strategy is to manipulate the reported first choice by listing a less demanded school (skipping-the-top). The second advised strategy is to reveal truthfully the most preferred choice and manipulate the second choice by listing a school that is most likely still available in the second round (skipping-the-middle). Our setup is designed to bring out both manipulations. In equilibrium under BOS, students use skipping-the-middle strategies in our first preference environment, and a majority of students uses skipping-the-top strategies in our second preference environment.

Because appropriate manipulation takes these simple forms in our design, we can clearly identify students that fail at strategizing. They are worse off in both environments as they enjoy a lower chance of being admitted in round 1 or 2 of BOS; as a result they are over-represented at the worst school. If a failure to strategize well is associated with a lower cognitive ability, ability segregation emerges under BOS. However, BOS dominates DA in ex-ante efficiency if a sufficient number of players strategize appropriately.

\footnotetext{
${ }^{3}$ Because ties at over-demanded schools are broken randomly, and cautionary motives are known to be an important driver of behavior in school choice [e.g. He, 2014], we also elicit risk preferences.

${ }^{4}$ Ties are broken according to a centralized lottery.
} 
Results can be summarized as follows. We find strong support for the leveling-the-playing-field hypothesis. Under BOS low ability subjects earn significantly lower payoffs than high ability ones in both preference environments while differences are smaller and (mostly) not significant under DA. Low ability students report truthfully more often than high ability ones under BOS. This is not the only mistake they are more prone to. They also report truthfully less often under DA, and tend to be more over-cautious. More generally, high ability subjects' strategies are more responsive to changes both in the mechanism and the preference environment. Low ability subjects are found at particular disadvantage when required to manipulate their second listed school. We argue this is due to the higher strategic complexity of this type of manipulation.

As a consequence, substantial ability segregation emerges under BOS, where low ability students are over-represented at the worst school. In the preference environment where subjects should skip the middle, the other schools admit up to 45 percent more high ability students than the worst school. In contrast, the ability distributions at schools are harmonized under DA.

Overall, average payoffs are close to the equilibrium predictions under DA. While players fall short of the equilibrium benchmark under BOS, average payoffs are still significantly higher than under DA in both preference environments. Those gains are mostly concentrated in the hands of high ability subjects. Thus, our results highlight a substantial trade-off between efficiency and equality in school choice mechanisms.

Starting from Chen and Sönmez [2006], a growing literature has addressed school choice with the use of laboratory experiments, exploiting the advantage of controlling students' preferences by design [Calsamiglia et al., 2010; Chen et al., 2015; Chen and Kesten, 2012; Klijn et al., 2013; Pais and Pintér, 2008]. These papers are mostly interested in comparing truth-telling rates, and identifying the rules of thumb used under different mechanisms. Featherstone and Niederle [2014] are closer to our work, as they try to ascertain how close to equilibrium students can get under BOS. First, they show subjects cannot play equilibrium under BOS when this requires manipulation mostly because of failures at skipping-the-middle. Second, they demonstrate truth-telling is often played under BOS in the special case where it can be implemented as an ordinal Bayes Nash equilibrium. They conclude that, in those cases, BOS may resolve the conflict between equality and efficiency.

Using data from applications in Boston, Abdulkadiroğlu et al. [2005] show that many students list below the first choice schools that are in fact unavail- 
able after the first round of the Boston mechanism. A number of papers have recently addressed the empirical difficulty of not observing students' preferences in the field. Using data from Barcelona, Calsamiglia and Güell [2014] find that the 'safety' of a school is one of the main determinants of listing it first. This fact and the presence of naive applicants induces important inequalities in how school choice affects different households. He [2014] studies school allocation in Beijing under the Boston Mechanism. His data stems from a school district of four schools which coincides with our experimental setup. Using estimated preferences, he finds that safe strategies are played too often, but finds no evidence that wealthier or more-educated parents are better at strategizing. Assuming truthful reports under DA, he finds that a switch to DA would yield utility losses for most parents.

The paper is organized as follows. Section 2 introduces the school choice environments. Section 3 presents the experimental design and procedures. Hypotheses are found in Section 4, and results follow in Section 5. Section 6 concludes.

\section{The school choice problem}

We consider situations where 16 students, $i \in I$, compete for seats at one of 4 schools, $s \in S=\{A, B, C, D\}$, with 4 seats each. Students' preferences are given by their type, $t_{i} \in T=\{1,2,3,4\}$, and there are four students of each type. Eventually, each student $i$ is admitted to a school $s$ and receives a payoff $p_{i}=p\left(s, t_{i}\right)$ that depends on both the school $s$ and her own type $t_{i}$.

We apply to this general set-up two different matching algorithms and two different preference environments. Students are informed about payoffs and the rules of the game. We assume players are risk neutral, and discuss the role of risk aversion separately. To derive equilibrium predictions, we analyse the game under the assumption of complete information.

In broad strokes, preferences in both environments are such that all students would rank schools alphabetically. However, some types receive a bonuspayoff from admittance to school $A, B$ or $C$ that influences the intensities of preferences and in some cases changes the preference order over schools. Hence, we aim to capture both heterogeneity in preferences and a strong correlation based on differences in school quality - with D being the worst school. We choose 4 schools to provide the strategic depth necessary to observe 'skipthe-middle' strategies; we choose schools of size four to limit the influence of 
own applications on the pool of all applicants at a particular school.

\subsection{Mechanisms}

To match students and schools we consider the Boston Mechanism ${ }^{5}$ - abbreviated as BOS - as well as the Deferred Acceptance Mechanism ${ }^{6}$ - abbreviated as DA. Under both mechanisms, students report a ranking of schools $\succ_{i}$, i.e. a strict linear order on $S$. To break ties among applicants, we apply a centralized lottery that draws a different number $l_{i}$ between 1 and 16 for each student, where each of the 16 ! lottery draws is equally likely. The mechanisms proceed as described below.

BOS - Boston Mechanism

ROUND 1. Student apply at the school that they ranked first. If there are at most 4 applicants at a school, all are admitted. If there are more applicants, the school admits applicants in order of their lottery number and up to capacity.

ROUND $k>1$. Students not yet admitted apply at the school that they ranked at the $k^{\text {th }}$ position. Schools admit new applicants in order of their lottery number and up to capacity.

With as many seats as students, each student is admitted to some school when the algorithm terminates after at most 4 rounds.

DA - Deferred Acceptance Mechanism

ROUND 1. Students apply at the school that they ranked first. Schools preliminarily accept applicants in the order of their lottery number and up to capacity. Any remaining applicants are rejected.

ROUND $k>1$. Students preliminarily accepted apply again at the same school. Student rejected in the previous round at a school they ranked $\mathrm{m}^{\text {th }}$ on their list, now apply at the school they ranked at the $(m+1)^{\text {th }}$ position. Schools preliminarily accept applicants in the order of their lottery number and up to capacity. Any remaining applicants are rejected.

With as many seats as students, and each school only rejecting applicants once it has reached capacity, we arrive at a point where each student is preliminarily accepted - at this point, the mechanism terminates and acceptance becomes final.

\footnotetext{
${ }^{5}$ Also known as Immediate Acceptance Mechanism.

${ }^{6}$ Also known as Gale-Shapley Mechanism
} 
TABle 1: PAyOFFS IN P1 (LEFT PANEL) AND P2 (RIGHT PANEL)

\begin{tabular}{c|cccc|cccc}
\hline $\mathrm{p}\left(\mathrm{s}, \mathrm{t}_{\mathrm{i}}\right)$ & $\begin{array}{c}\text { School } \\
\text { A }\end{array}$ & $\begin{array}{c}\text { School } \\
\text { B }\end{array}$ & $\begin{array}{c}\text { School } \\
\text { C }\end{array}$ & $\begin{array}{c}\text { School } \\
\text { D }\end{array}$ & $\begin{array}{c}\text { School } \\
\text { A }\end{array}$ & $\begin{array}{c}\text { School } \\
\text { B }\end{array}$ & $\begin{array}{c}\text { School } \\
\text { C }\end{array}$ & $\begin{array}{c}\text { School } \\
\text { D }\end{array}$ \\
\hline Type 1 & 20 & 10 & 6 & 0 & 20 & 11 & 7 & 0 \\
Type 2 & 16 & 17 & 6 & 0 & 16 & 15 & 7 & 0 \\
Type 3 & 16 & 10 & 8 & 0 & 16 & 11 & 11 & 0 \\
Type 4 & 16 & 10 & 6 & 0 & 16 & 11 & 7 & 0 \\
\hline
\end{tabular}

Notes: each cell represents the payoff a student of type $t_{i}$ obtains when admitted at school $s$ in the relevant preference environment.

\subsection{Preference environment 1}

Payoffs for preference environment 1 (henceforth P1) are given in the left panel of Table 1. Students agree that $\mathrm{D}$ is the worst school with an associated payoff of zero. They also agree in ranking $C$ third, but type 3 students earn a higher payoff than others at that school. Type 2 students prefer $B$ to $A$, while all other students prefer $A$ to $B$. Students of type 1 earn a higher payoff at $A$.

Under DA, truth-telling is dominant. Hence, if players play accordingly, types 1,3 and 4 report $A \succ_{i} B \succ_{i} C \succ_{i} D$ while students of type 2 report $B \succ_{i}$ $A \succ_{i} C \succ_{i} D$. The associated average expected payoff is 9.33. Under BOS, players have incentives to strategize, which yields the following equilibria.

\section{Equilibria BOS-P1.}

In every pure strategy Nash equilibrium of the game induced by BOS-P1 :

- 11 students report $\mathrm{A} \succ_{i} \mathrm{C} \succ_{i} \mathrm{~B}, \mathrm{D}$ : all type 1 and 7 out of the 8 type 3 and 4

- 5 students report $\mathrm{B} \succ_{i} \mathrm{C} \succ_{i} \mathrm{~A}, \mathrm{D}$ : all type 2 and 1 out of the 8 type 3 and 4

Under an equilibrium strategy profile, if a student is rejected at her first choice, the only remaining seats in round 2 are seats at schools C and D. Hence, it is crucial to manipulate the second choice by ranking $C$ second.

If in equilibrium everyone ranks $C$ second, it does not matter which school is ranked third. Thus, equilibrium under BOS-P1 is essentially unique - it is unique up to redundant strategies and the identity of the one player of type 3 or 4 applying at B. Expected average payoff is 9.9.7

The intuition behind this equilibrium is as follows. Since there are at least four students that like schools $A$ and $B$ best, these schools are filled in the first round. Moreover, since the payoff at $D$ is zero, everyone rejected at $A$

\footnotetext{
${ }^{7}$ It is 9.90 if some type 3 applies at B and 9.93 if the fifth player applying at B is of type 4 .
} 
or $B$ in round one should apply at $C$ in the second round. Showing that $C$ is never ranked first in any equilibrium, and establishing who ranks $A$ or $B$ first requires additional calculation that we refer to Appendix A.

\subsection{Preference environment 2}

Payoffs in preference environment 2 (henceforth $\mathrm{P} 2$ ) are given in the right panel of Table 1 . All students agree that $A$ is better than $B$, and the payoff from $A$ is highest for students of type 1 . Students of types 1,2 , and 4 prefer $B$ to $C$, and the payoff from B is highest for students of type 2. Students of type 3 earn a higher payoff at $C$ compared to others, and are indifferent between $B$ and C. All students prefer C over D.

Under DA, if players apply dominant strategies, types 1,2 and 4 report $\mathrm{A} \succ_{i} \mathrm{~B} \succ_{i} \mathrm{C} \succ_{i} \mathrm{D}$, while students of type 3 report either $\mathrm{A} \succ_{i} \mathrm{~B} \succ_{i} \mathrm{C} \succ_{i} \mathrm{D}$ or $\mathrm{A} \succ_{i}$ $\mathrm{C} \succ_{i} \mathrm{~B} \succ_{i} \mathrm{D}$. The associated average expected payoff is between 9.25 and 9.58 . Under BOS, players' incentives to strategize yield the following equilibria:

\section{Equilibria BOS-P2.}

In every pure strategy Nash equilibrium of the game induced by BOS-P2 :

- 7 students report $\mathrm{A} \succ_{i} \mathrm{~B}, \mathrm{C}, \mathrm{D}$ : all type 1 and three of type 4

- 5 students report $\mathrm{B} \succ_{i} \mathrm{~A}, \mathrm{C}, \mathrm{D}$ : all type 2 and one of type 4

- 4 students report $\mathrm{C} \succ_{i} \mathrm{~A}, \mathrm{~B}, \mathrm{D}$ : all type 3

Under these strategy profiles, the only remaining seats in round two are seats at school D, so that the reported first choice and hence the decision on whether to skip-the-top becomes crucial. In equilibrium, more than half of all players decide to manipulate by listing another than their most preferred school first. The associated average expected payoff is 10.16. All calculations establishing the above profiles as the only equilibria are referred to Appendix A.

\section{Experimental design and procedures}

Each session consisted of a test of cognitive ability, a risk elicitation task, and ten rounds of a school allocation game with subjects in the role of students. An English version of the experimental instructions, control questionnaires, and screenshots for all tasks can be found in Appendix B. 


\subsection{Cognitive ability and risk aversion}

Each session started with a computerized version of Raven's Progressive Matrices test. The Raven test is a leading non-verbal measure of analytic intelligence [Carpenter et al., 1990; Gray and Thompson, 2004], and Raven test scores are associated with the degree of sophistication in the beauty contest [Gill and Prowse, 2015], with the performance in Bayesian updating [Charness et al., 2011], and with more accurate beliefs [Burks et al., 2009]. Each question of the test asks to identify the missing element that completes a visual pattern from a list of candidates. ${ }^{8}$ The Standard Progressive Matrices version of the Raven test consists of 60 questions split into 5 blocks of increasing difficulty, labeled A-E, with 12 questions in each. We used blocks C, D and E, for a total of 36 questions. We gave the subjects 5 minutes to complete each of blocks $C$ and $\mathrm{D}$, and 8 minutes to complete block E. Within each block, subjects could move back and forth between the questions, eventually skipping some, and changing their previous answers. Participants received 0.1 ECU for each correct answer.

After the Raven test, subjects played the bomb risk elicitation task (BRET) developed by Crosetto and Filippin [2013]. For that, subjects have to decide how many out of 100 boxes to collect, one of which contains a bomb. ${ }^{9}$ The bomb is placed randomly among the boxes, and subjects are unaware of where their bomb is located. If a subject does not collect the bomb, he receives 0.1 ECU for each collected box. He receives zero if he collects the bomb. The number of boxes collected maps into the degree of risk aversion: the more boxes a subjects collects the less risk averse (or the more risk loving) he is, where collecting 50 boxes corresponds to risk neutrality. We choose this task because it is easy to explain and intuitive to perform, features that are particularly desirable in a design that is rather demanding in cognitive terms.

\subsection{Treatments}

The school allocation game accords with the environment described in Section 2. Sixteen students, four for each preference type, are allocated to four schools, according to their submitted lists and a random priority ordering. The treatment variables are the allocation mechanism and the preference environment. The allocation mechanism can be either DA or BOS, the preference environ-

\footnotetext{
${ }^{8}$ See Appendix B for an example.

${ }^{9}$ Boxes are collected sequentially: the player needs to press a 'Stop' button to end the collection of boxes. See Appendix B for a screenshot of the decision screen.
} 
ment P1 or P2, resulting in four treatments. In each session subjects play five consecutive rounds of the school choice game under each of the two preference environments, for a total of ten rounds, always under the same allocation mechanism. That is, we vary the allocation mechanism between subjects, and the preference environment within subjects. We vary the order of P1 and P2 across sessions to control for order effects.

We classify each subject as either of high cognitive ability or of low cognitive ability according to whether his test score is in the top or bottom half of the distribution of scores in his session. ${ }^{10}$ Since we want preference types to be balanced with respect to cognitive ability, we assign two high and two low subjects to each type. Subject to this constraint, a new preference type is assigned randomly to each player in every new round.

A random lottery generates a priority ordering in each round. After all sixteen subjects have submitted their lists, the allocation is computed according to the relevant mechanism. Subjects are informed of their assigned school, their lottery number, and their payoff in ECU in that round.

\subsection{Experimental procedures}

The computerized experiment was run at the WZB-TU Experimental Lab in Berlin, in autumn 2015, and involved 192 subjects, distributed over 12 experimental sessions. Sessions took on average 75 minutes. The computerized program was developed using Z-tree [Fischbacher, 2007]. Table 2 summarizes sessions' details. Each subject participated only in one session.

All sessions followed an identical procedure. Subjects were randomly assigned to cubicles in the lab. Instructions were read aloud before each task. To ensure everybody understood the tasks, we conducted a control questionnaire before the BRET and the school choice game. For the school choice game, this included finding the allocation in a simple school choice problem, given the submitted lists and the priority ordering. The tasks would only start after every subject had correctly completed the questionnaire. To get subjects used to the decision environment, we run a trial round of BRET where no ECU could be earned, before the payoff-relevant one.

At the end of the school choice game, subjects were asked to fill in a questionnaire. We gathered qualitative information about their strategies, and their opinions regarding school choice. We also collected data on whether

\footnotetext{
${ }^{10}$ We break ties using the amount of time used to complete the Raven test. If ties still remain we break them at random.
} 
TABLE 2: SESSIONS

\begin{tabular}{ccccc}
\hline Session No. & Date & Participants & Mechanism & Environment order \\
\hline $\mathbf{1}$ & September 2015 & 16 & BOS & P1-P2 \\
$\mathbf{2}$ & September 2015 & 16 & BOS & P1-P2 \\
$\mathbf{3}$ & September 2015 & 16 & BOS & P1-P2 \\
$\mathbf{4}$ & September 2015 & 16 & DA & P1-P2 \\
$\mathbf{5}$ & September 2015 & 16 & DA & P1-P2 \\
$\mathbf{6}$ & September 2015 & 16 & DA & P1-P2 \\
$\mathbf{7}$ & November 2015 & 16 & BOS & P2-P1 \\
$\mathbf{8}$ & November 2015 & 16 & BOS & P2-P1 \\
$\mathbf{9}$ & November 2015 & 16 & BOS & P2-P1 \\
$\mathbf{1 0}$ & November 2015 & 16 & DA & P2-P1 \\
$\mathbf{1 1}$ & November 2015 & 16 & DA & P2-P1 \\
$\mathbf{1 2}$ & November 2015 & 16 & DA & P2-P1 \\
\hline
\end{tabular}

Notes: Mechanism indicates whether BOS or DA were implemented. Environment order indicates whether the five rounds of preference environment 1 were run before (P1-P2) or after (P2-P1) preference environment 2.

they had faced the Raven or a similar test before, and on whether they were used to playing mind puzzles.

Subjects were told they would have been paid according to the ECU earned in the Raven test, in the BRET and in one round of the school choice game selected at random by the computer. The corresponding rounds were paid according to the exchange rate: $1 \mathrm{ECU}=.70 €$. Subjects could earn between 0 and 14 Euros from the school choice game, between 0 and 2.60 Euros from the Raven test, and between 0 and 7.00 Euros from the BRET. The average payment, including 5 Euros of show-up fee, was 16.20 Euros.

\section{Hypotheses}

As a convention, we label as Truthful the strategy where the reported rank order list coincides with the true preferences. ${ }^{11}$ We label Safe-Naive (SN) the strategy where the reported preferences are manipulated by swapping the order of the two most preferred schools, listing the less popular school first and the most popular school A second. ${ }^{12}$ Under Skipping-The-Top (STT) applicants list their second most preferred school first instead of the most popular school

\footnotetext{
${ }^{11}$ For a student of type 3 in $\mathrm{P} 2$ who is indifferent between $\mathrm{B}$ and $\mathrm{C}$, reporting $\mathrm{A} \succ \mathrm{C} \succ \mathrm{B} \succ \mathrm{D}$ and $\mathrm{A} \succ \mathrm{B} \succ \mathrm{C} \succ \mathrm{D}$ are both considered truthful.

${ }^{12}$ Not applicable to strategies of type 2 in P1. For a student of type 3 in P2, submitting $\mathrm{B} \succ \mathrm{A} \succ \mathrm{C}, \mathrm{D}$ or $\mathrm{C} \succ \mathrm{A} \succ \mathrm{B}, \mathrm{D}$ counts as $\mathrm{SN}$.
} 
A and list their third most preferred school second. ${ }^{13}$ Under Skipping-TheMiddle (STM), an applicant lists her most preferred school first and the third most preferred school C second. ${ }^{14}$

As shown in section 2, for BOS-P1 equilibrium predicts that in the first round there are 11 applicants at school A and 5 applicants at school B. All students list $C$ second. All but one student play STM. In BOS-P2, equilibrium predicts that in the first round there are 7 applicants at school A, 5 applicants at school B and 4 applicants at school C. A majority of players uses SN or STT. All reports are truthful under DA-P1 and DA-P2. Hypothesis 1 posits that comparative statics qualitatively match equilibrium predictions.

Hypothesis 1. The fraction of truthful reports is lower under BOS than under DA, in both $\mathrm{P} 1$ and $\mathrm{P} 2$. The converse holds for STM in $\mathrm{P} 1$, and for SN and STT in $\mathrm{P} 2$.

The ex-ante expected payoff in equilibrium - i.e., before types and lottery numbers are drawn - is between 9.9 and 9.95 in BOS-P1, equal to 9.33 in DA-P1, equal to 10.87 in BOS-P2, and at most 9.58 in DA-P2. ${ }^{15}$ BOS increases expected payoff relative to DA by $6.1 \%-6.6 \%$ in $\mathrm{P} 1$ and by at least $13.5 \%$ in $\mathrm{P} 2$. The intuition for this is that efficiency increases when a student of a certain type is assigned to the school where he earns a higher payoff relative to students of other types. Strategizing works in this direction, because students gain priority at the school they rank higher relative to others. We hypothesize BOS dominates DA in ex-ante efficiency terms.

Hypothesis 2. Subjects' average payoff is higher under BOS than under DA in both preference environments.

We expect subjects with a lower Raven score (Low) to be less able to identify optimal strategies than subjects with a higher Raven score (High). ${ }^{16}$ In principle, this could be due to either random errors or systematic biases (or both). We follow Pathak and Sönmez [2008] and hypothesize Low subjects are naive, i.e., they are biased towards truthful reporting, while High subjects

\footnotetext{
${ }^{13}$ Not applicable to strategies of type 2 in P1. For a student of type 3 in P2, submitting $B, C \succ A, D$ counts as STT.

${ }^{14}$ Not applicable to strategies of type 3 in P2. For a student of type 2 in P1, submitting $\mathrm{B} \succ \mathrm{C} \succ A, \mathrm{D}$ counts as STM.

${ }^{15}$ The expected payoff in BOS-P1 depends on the selected equilibrium, i.e. on the identity of the fifth applicant at B. The expected payoff in DA-P2 depends on the report of students of type 3, who are indifferent between $B$ and $C$.

${ }^{16}$ Considering that cognitive ability is to a large extent genetically inherited [see, e.g. Plomin, 1999], and for the sake of simplicity, we consider parents and children as a single decision maker that applies at schools and attend the school she is assigned to.
} 
are strategic and best respond. Then compared to the equilibria in BOS-P1, we still find $A$ and $B$ filled in the first round, but fewer applicants at $C$ in the second round. This increases the chances of strategic subjects to be admitted at $C$ should they be rejected in round one. Hence, with a sufficiently high fraction of naive applicants, strategic subjects will take the risk of applying at their true first choice in the first round, even if that is the most competitive school A. ${ }^{17}$ Then, naive and strategic applicants only differ in whether they rank $C$ second, the latter deciding to skip-the-middle.

Similarly, in BOS-P2, strategic players of type 2 and 4 will initially apply at $B$ so that $B$ is filled in round one - at least as long as there are in total (weakly more than) four strategic students of types 2 and $4 .{ }^{18}$ With some naive student(s) of type 3, C will still be available in round 2, so that all strategic players will rank it second. In consequence, naive and strategic players differ in that the later will use skip-the-top and skip-the-middle strategies. ${ }^{19}$

Hypothesis 3. Low subjects are more likely than High subjects to report truthfully under BOS. High subjects are more likely than Low subjects to play STM in BOS-P1, STT and STM in BOS-P2.

We note that the second part of Hypothesis 3 may also be true when High subjects play an equilibrium strategy (see Section 2). This is due to the fact that appropriate strategizing can take only few simple forms in our context, which is one of the main advantages of our design. On the other hand, this implies we cannot test for subjects beliefs on the strategic ability of opponents. ${ }^{20}$

A bias towards truth-telling puts Low subjects at a disadvantage under BOS. Being truthful when one should skip the middle implies losing chances of being admitted in the second and third round, because capacities at schools A, B and C are reduced or exhausted in rounds one and two. Being truthful when one should skip the top also implies over-competing for scarce seats at the most popular school. For instance, if half of the subjects are naive Low, and High subjects best respond to them, the expected payoff of a Low subject

\footnotetext{
${ }^{17}$ See Appendix A, Naive and strategic players in BOS-P1.

${ }^{18}$ See Appendix A, Naive and strategic players in BOS-P2.

${ }^{19}$ Strategic players of type 3 will skip-the-top or submit $A \succ_{i} C \succ_{i} B \succ_{i} D$ which for them counts as truthful. See Basteck and Mantovani [2016] for an explicit characterization of the pseudo-equilibria when there are exactly to Low and two High applicant for each preference type.

${ }^{20}$ Nevertheless, behavior of High subjects when they best respond to naive Low subjects is not identical to that in equilibrium, providing us some clues on their awareness of the strategic ability of the others. Most notably, when High subjects best respond to naive Low subjects, they rank C second in BOS-P2, while their second choice is irrelevant in equilibrium.
} 
is 8.58 in BOS-P1 and 6.58 in BOS-P2, the expected payoff of a High subject is 11.66 in BOS-P1 and 12.27 in BOS-P2. Since truth-telling is a dominant strategy in DA, DA should level the playing field.

Hypothesis 4. The average payoff for High subjects is larger than for Low subjects in BOS-P1 and BOS-P2. Average payoffs for Low and High subjects do not differ in $\mathrm{DA}-\mathrm{P} 1$ and DA-P2.

Finally, all subjects agree that D is the worst school. Under BOS, if Low subjects are less able to strategize well, they are less able to avoid being assigned to D. For instance, if half of the subjects are naive Low, and High subjects best respond to them, under BOS-P1 in expected terms schools $A$ and $B$ are balanced, school $C$ admits only High, school D only Low subjects. Under BOS-P2, school A admits more Low, school C more High, school B only High and school D only Low subjects. Under DA all schools should be balanced. Moreover, any departure from truth-telling in the ranking of the first three schools does not translate into a higher probability of being assigned to D. Thus, even under more general assumptions on the strategic behavior of Low subjects, as long as they rank D last, they are not assigned to D with a higher probability than High subjects under DA.

Hypothesis 5. Low subjects are over-represented at school D under BOS, but not under $D A$.

\section{Results}

Table 3 provides an aggregate glimpse of the allocation process. It shows in which round seats at the different schools are assigned to their final match. School $A$ is always filled in the first round. ${ }^{21}$ The same holds for School B, except for DA-P2. Three out of four seats at school $\mathrm{C}$ are no longer available after round 2 under BOS. More than one third of them are already assigned in round 1 in BOS-P2.

Around 75 percent of reports are truthful under DA-P1 and DA-P2. The same figure is 51 percent under BOS-P1 and BOS-P2. School $C$ is ranked second 27 (23) percent of the time under BOS-P1 (BOS-P2), only 6 (8) percent under DA-P1 (DA-P2). Manipulation of the first listed school account for between

\footnotetext{
${ }^{21}$ First round matches are temporary in DA. However, rejected students have on average lower lottery numbers, and it is hard for them to win a seat that was assigned to someone else, especially at over-demanded schools.
} 
TABLE 3: SEAT ALLOCATION DYNAMiCS

\begin{tabular}{lccccc}
\hline & & DA-P1 & BOS-P1 & DA-P2 & BOS-P2 \\
\hline \multirow{2}{*}{ School A } & round 1 & $94 \%$ & $100 \%$ & $100 \%$ & $100 \%$ \\
& round 2 & $100 \%$ & - & - & - \\
\multirow{2}{*}{ School B } & round 1 & $85 \%$ & $100 \%$ & $42 \%$ & $93 \%$ \\
& round 2 & $100 \%$ & - & $100 \%$ & $100 \%$ \\
\multirow{2}{*}{ School C } & round 1 & $12 \%$ & $16 \%$ & $25 \%$ & $36 \%$ \\
& round 2 & $20 \%$ & $74 \%$ & $47 \%$ & $72 \%$ \\
\multirow{2}{*}{ School D } & round 1 & $0 \%$ & $1 \%$ & $1 \%$ & $2 \%$ \\
& round 2 & $1 \%$ & $3 \%$ & $3 \%$ & $3 \%$ \\
\hline
\end{tabular}

Notes: the table shows the (cumulative) percentage of seats of each school that are allocated in the first two rounds of the allocation procedure in the different treatments.

TABLE 4: ACROSS TREATMENT DIFFERENCES

\begin{tabular}{llcccccccccc}
\hline & Sample & \multicolumn{2}{c}{ Truthful } & \multicolumn{2}{c}{ SN } & \multicolumn{2}{c}{ STT } & \multicolumn{3}{c}{ STM } & \multicolumn{2}{c}{ Exp. Payoff } \\
& & Z & P-val & Z & P-val & Z & P-val & Z & P-val & Z & P-val \\
\hline \multirow{2}{*}{ DA vs BOS } & P1 & $\mathbf{2 . 9 1}$ & $\mathbf{. 0 0}$ & -.80 & .42 & $\mathbf{- 2 . 7 6}$ & $\mathbf{. 0 1}$ & $\mathbf{- 2 . 8 8}$ & $\mathbf{. 0 0}$ & -1.92 & .05 \\
& P2 & $\mathbf{2 . 8 1}$ & $\mathbf{. 0 0}$ & $\mathbf{- 2 . 5 4}$ & $\mathbf{. 0 3}$ & $\mathbf{- 2 . 7 3}$ & $\mathbf{. 0 1}$ & $\mathbf{- 2 . 1 9}$ & $\mathbf{. 0 3}$ & $\mathbf{- 2 . 4 1}$ & $\mathbf{. 0 2}$ \\
P1 vs P2 & DA & 1.16 & .25 & -1.58 & .11 & -1.94 & .05 & 0.315 & .75 & & \\
& BOS & -.11 & .92 & $\mathbf{- 2 . 2 0}$ & $\mathbf{. 0 3}$ & $\mathbf{- 2 . 2 0}$ & $\mathbf{. 0 3}$ & $\mathbf{2 . 2 0}$ & $\mathbf{. 0 3}$ & & \\
\hline
\end{tabular}

Notes: the table reports for each of the listed variables: the Wilkoxon rank-sum test, and corresponding Pvalue, on the difference between DA and BOS within each preference environment; the Wilkoxon signedrank test for the differences between $\mathrm{P} 1$ and $\mathrm{P} 2$, within each mechanism. A positive statistic means a higher value for DA (P1). The statistic is computed using one observation per session. Expected payoff is computed using a recombinant strategies procedure with 1000 recombinations for each subject in each period, and an identical number of tie breakers. Bold indicates significance at the .05 level.

14 and 21 percent of the strategies used under DA-P1, DA-P2, and BOS-P1. The figure is 42 percent in BOS-P2. Non-parametric tests on differences across treatments are shown in Table 4 . Every test is based on one observation per session. We find evidence that significantly fewer truthful lists are submitted in BOS with respect to DA. Under BOS-P1, subject use STM and STT significantly more relative to DA-P1. Under BOS-P2 they also employ significantly more SN strategies relative to DA-P2. When comparing $\mathrm{P} 1$ to $\mathrm{P} 2$, there are no significant differences under DA, while P2 induces more SN and STT, and less STM strategies than P1 under BOS. Thus, while players fall short of the theoretical benchmark, all treatments shift behavior in the direction predicted by equilibrium, supporting Hypothesis 1.

Result 1. DA induces higher rates of truth-telling relative to BOS. BOS-P1 induces 
more STM, BOS-P2 more SN and STT strategies.

Payoffs earned in the experiment depend to a large extent on the random priorities, and on the strategies used in that particular period by the other subjects in the session. To compare the payoffs across treatments and subjects we use a recombinant estimation technique similar to the one employed by Chen and Sönmez [2006]. The procedure works as follows. Start by picking the strategy of the first subject in the first period, and match it with fifteen strategies drawn at random among those used in the first period in all sessions of the same treatment, under the constraint that there are four players for each type in the resulting virtual game. Given these sixteen strategies, seats are assigned based on a new random priority ordering. Repeat $n$ times, always rematching the same strategy, and create $n$ random samples, each with its own priority ordering, and corresponding allocation. Implement this procedure for all subjects and all periods. We choose $n=1000$. Because subjects' strategies are not statistically independent within a session - the game is repeated - we cannot run parametric tests on the average payoffs earned across recombinations (as done by Chen and Sönmez [2006]). In the following, we consider each individual average payoff over recombinations as the expected payoff of the corresponding subject in that period. ${ }^{22}$

The empirical average expected payoff is 9.20 under DA-P1, 9.63 under BOS-P1, 9.58 under DA-P2, and 9.94 under BOS-P2. In equilibrium, the corresponding figures would be (approximately, see Section 4) 9.33, 9.9, 9.58 and 10.87. Subjects are close to equilibrium payoffs under DA, less so under BOS. The last columns in Table 4 show the efficiency gains of BOS over DA are significant in $\mathrm{P} 2$, but not in $\mathrm{P} 1 .^{23}$ A parametric approach to the same question is taken in Table 5, where we also try to account for the multiple factors that may influence one's expected payoff through regression analysis. The dependent variable is the expected payoff obtained from the recombinant estimation technique. All models are random-effects panel regressions, where standard errors are clustered at the session level. Models (4) and (5) confirm our previous findings for P2. Models (1) and (2) detect a significant efficiency gain also in BOS-P1 relative to DA-P1. ${ }^{24}$

Result 2. BOS dominates DA in ex-ante efficiency, confirming Hypothesis 2.

\footnotetext{
${ }^{22}$ While we think this approach is most correct, we note that all of our results hold when we use the raw payoffs obtained in the experiment.

${ }^{23}$ Note the P-value for $\mathrm{P} 1$ is precisely .05 .

${ }^{24} \mathrm{As}$ it should be expected, in (4) and (5) lower risk aversion/higher risk propensity is associated with higher payoffs.
} 


\begin{tabular}{|c|c|c|c|c|c|c|}
\hline & \multicolumn{6}{|c|}{ Dep. Var.: Expected payoff } \\
\hline & (1) & $\begin{array}{l}\text { P1 } \\
(2)\end{array}$ & (3) & $(4)$ & $\begin{array}{c}\text { P2 } \\
(5)\end{array}$ & (6) \\
\hline BOS & $\begin{array}{c}0.391^{* * *} \\
(0.133)\end{array}$ & $\begin{array}{l}0.427^{* * *} \\
(0.0969)\end{array}$ & $\begin{array}{c}0.126 \\
(0.138)\end{array}$ & $\begin{array}{l}0.305^{* * *} \\
(0.0949)\end{array}$ & $\begin{array}{l}0.332^{* * *} \\
(0.0827)\end{array}$ & $\begin{array}{l}0.206^{* * *} \\
(0.0719)\end{array}$ \\
\hline High & $\begin{array}{c}0.550^{* * *} \\
(0.153)\end{array}$ & $\begin{array}{c}0.508^{* * *} \\
(0.157)\end{array}$ & $\begin{array}{c}0.209 \\
(0.135)\end{array}$ & $\begin{array}{l}0.444^{* * *} \\
(0.0758)\end{array}$ & $\begin{array}{c}0.448^{* * *} \\
(0.103)\end{array}$ & $\begin{array}{l}0.323^{* *} \\
(0.148)\end{array}$ \\
\hline BOS*High & & & $\begin{array}{l}0.596^{* *} \\
(0.235)\end{array}$ & & & $\begin{array}{c}0.249 \\
(0.165)\end{array}$ \\
\hline age & & $\begin{array}{c}0.0225 \\
(0.0172)\end{array}$ & $\begin{array}{c}0.0193 \\
(0.0183)\end{array}$ & & $\begin{array}{c}0.000899 \\
(0.0199)\end{array}$ & $\begin{array}{c}-0.000463 \\
(0.0197)\end{array}$ \\
\hline female & & $\begin{array}{c}-0.408^{* *} \\
(0.159)\end{array}$ & $\begin{array}{c}-0.402^{* * *} \\
(0.151)\end{array}$ & & $\begin{array}{c}-0.0251 \\
(0.107)\end{array}$ & $\begin{array}{c}-0.0224 \\
(0.103)\end{array}$ \\
\hline period & & $\begin{array}{c}0.0128 \\
(0.0334)\end{array}$ & $\begin{array}{c}0.0128 \\
(0.0335)\end{array}$ & & $\begin{array}{c}0.0251 \\
(0.0305)\end{array}$ & $\begin{array}{c}0.0251 \\
(0.0305)\end{array}$ \\
\hline Type 2 & & $\begin{array}{c}1.117^{* * *} \\
(0.380)\end{array}$ & $\begin{array}{c}1.120^{* * *} \\
(0.379)\end{array}$ & & $\begin{array}{l}-0.200 \\
(0.267)\end{array}$ & $\begin{array}{c}-0.198 \\
(0.268)\end{array}$ \\
\hline Type 3 & & $\begin{array}{c}-1.052^{* * *} \\
(0.114)\end{array}$ & $\begin{array}{c}-1.050^{* * *} \\
(0.115)\end{array}$ & & $\begin{array}{l}0.0774 \\
(0.217)\end{array}$ & $\begin{array}{l}0.0774 \\
(0.218)\end{array}$ \\
\hline Type 4 & & $\begin{array}{c}-1.715^{* * *} \\
(0.177)\end{array}$ & $\begin{array}{c}-1.716^{* * *} \\
(0.178)\end{array}$ & & $\begin{array}{c}-1.033^{* * *} \\
(0.293)\end{array}$ & $\begin{array}{c}-1.036^{* * *} \\
(0.293)\end{array}$ \\
\hline order & & $\begin{array}{c}0.143 \\
(0.153)\end{array}$ & $\begin{array}{c}0.136 \\
(0.160)\end{array}$ & & $\begin{array}{c}-0.0383 \\
(0.155)\end{array}$ & $\begin{array}{r}-0.0412 \\
(0.160)\end{array}$ \\
\hline BRET & & $\begin{array}{c}0.0160^{* *} \\
(0.00639)\end{array}$ & $\begin{array}{c}0.0153^{* *} \\
(0.00616)\end{array}$ & & $\begin{array}{c}0.0106^{* *} \\
(0.00526)\end{array}$ & $\begin{array}{c}0.0103^{* *} \\
(0.00522)\end{array}$ \\
\hline _cons & $\begin{array}{l}8.916 * * * \\
(0.0665)\end{array}$ & $\begin{array}{c}8.082^{* * *} \\
(0.579)\end{array}$ & $\begin{array}{c}8.342^{* * *} \\
(0.637)\end{array}$ & $\begin{array}{l}9.415^{* * *} \\
(0.0675)\end{array}$ & $\begin{array}{c}9.056^{* * *} \\
(0.612)\end{array}$ & $\begin{array}{c}9.165^{* * *} \\
(0.618)\end{array}$ \\
\hline Obs. (groups) & $960(12)$ & $960(12)$ & $960(12)$ & $960(12)$ & $960(12)$ & $960(12)$ \\
\hline
\end{tabular}

Notes: the dependent variable is computed using recombinant strategies procedure with 1000 recombinations for each subject in each period, and an identical number of tie breakers. In parentheses we report robust standard errors, clustered at the session level. ${ }^{* * *},{ }^{* * *}$ : statistically significant at the $10 \%, 5 \%$ and $1 \%$ level, respectively. 
Figure 1: Distribution OF RAVEN SCORES

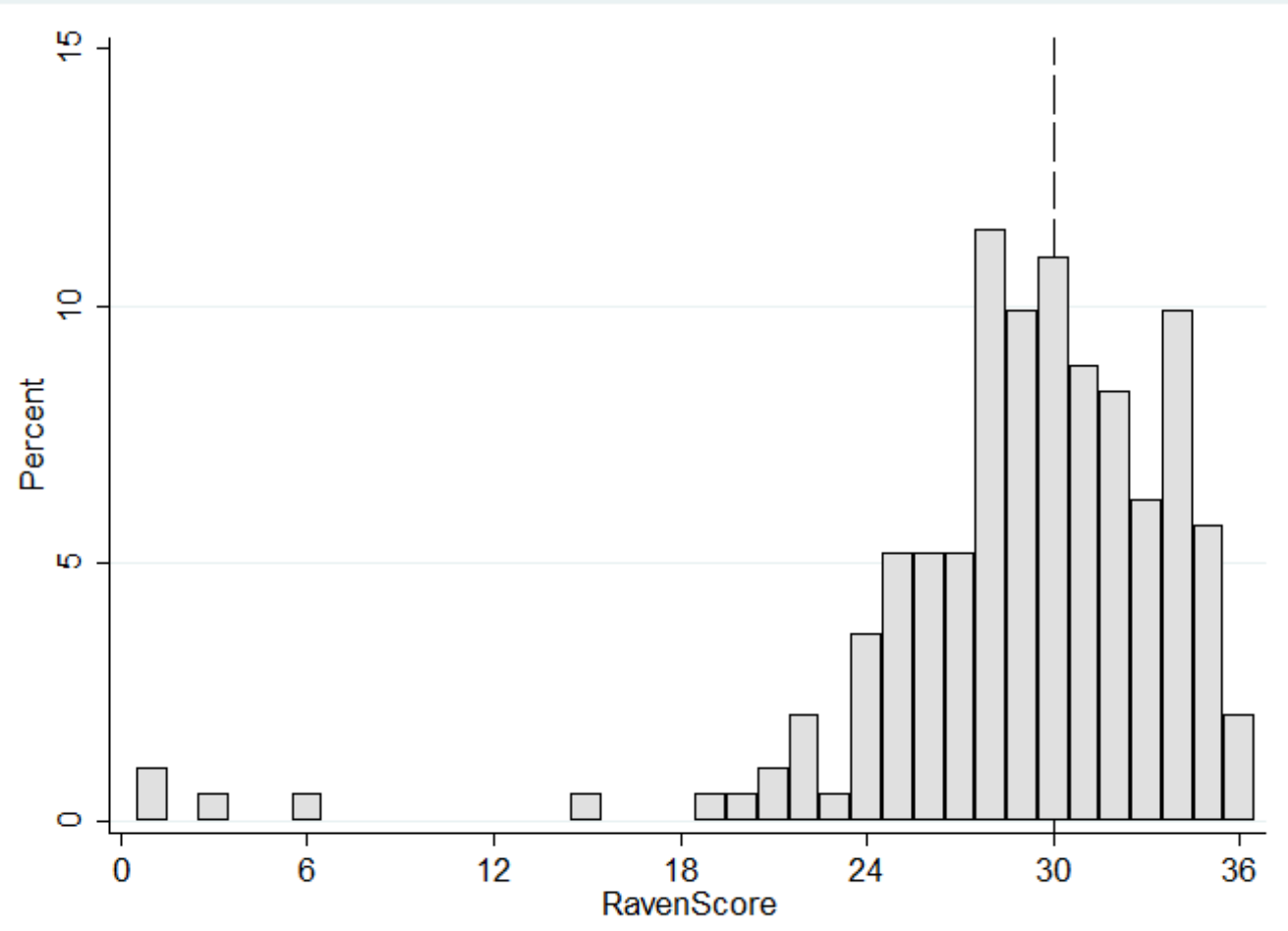

FIGURE 2: DISTRIBUTION OF RISK TASK CHOICES

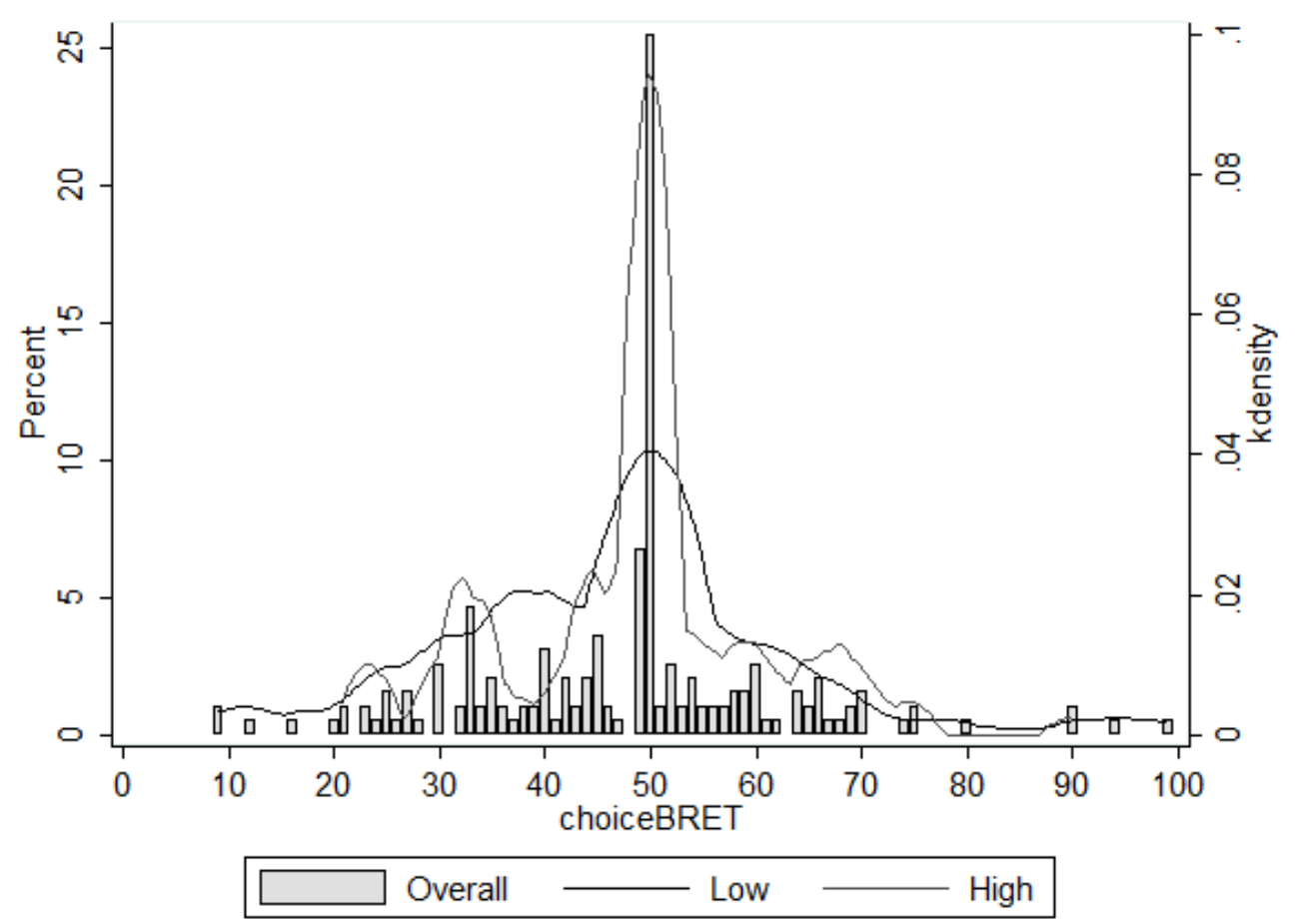


Figure 3: Players' strategies - P1

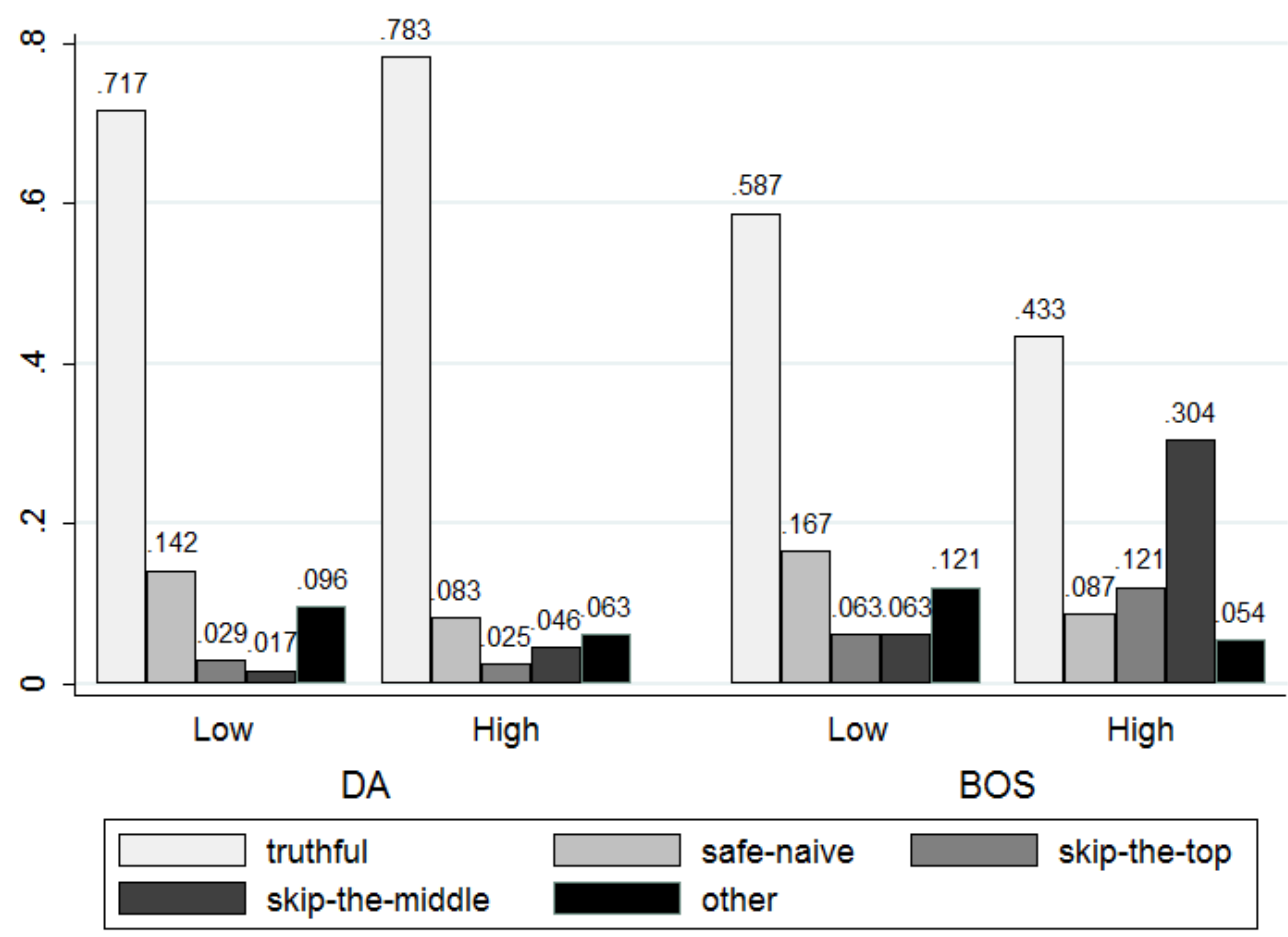

Figure 4: Players' Strategies - P2

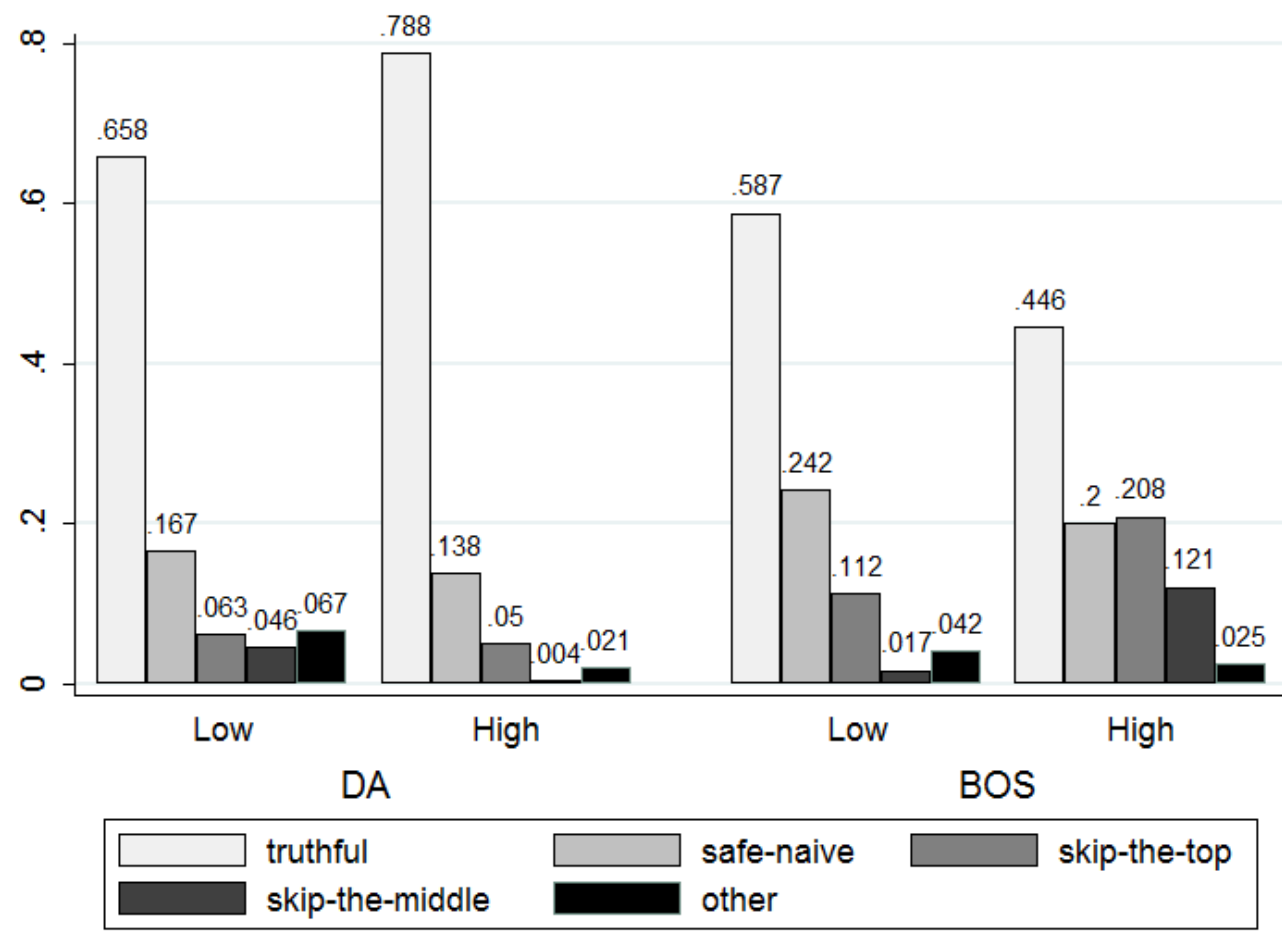


We turn to the comparison of High and Low subjects. Figure 1 reports the distribution of Raven scores and its median. ${ }^{25}$ For the analysis, we choose to split the overall sample between High and Low subjects, rather than keep using the classification adopted to allocate them within each session, because we observe some differences in the thresholds across sessions. Nevertheless we use on the whole sample the same criterion adopted within each session: we break ties in the partial ordering induced by Raven scores using the amount of time used to complete the test, where faster subjects receive a higher rank. If ties survive to this procedure, we break them at random. The median happens to be at a Raven score of 30, where all of the 18 minutes given are used to complete the test. Subjects that do strictly better than that are classified as High, others are classified as Low. Figure 2 reports the distribution of choices in the risk elicitation task. We overimpose the kernel densities for Low and High subjects. A larger number of High subjects are risk neutral relative to Low subjects. We do not detect a significant correlation between Raven scores and risk attitudes. ${ }^{26}$

Figures 3 and 4 show the distribution of strategies used by High and Low subjects in each treatment. The truth-telling rate of High subjects is higher than that of Low subjects under DA, and lower under BOS, in both P1 and P2. High subjects seem to respond to the treatments as expected: STM is played by around one third of them in BOS-P1, and SN snd STT are used to a relevant extent only in BOS-P2. Low subjects seem to adjust their strategies only marginally to the different treatments.

We run a multinomial logit on the strategies used to assess the effect that being High or Low has in different treatments. We estimate the marginal effects and test for the significance of differences in marginal effects. Results are reported in Table 6. The top panel reports differences between High and Low subjects in each treatment. The bottom panels report the difference between DA and BOS, in each preference environment, for Low and High subjects separately. Each cell can be interpreted as a difference in the probability of using the strategy of the corresponding column. Bold differences are significant at the 5 percent level. For instance, the probability of being truthful in DA-P2 is 12.6 percentage points higher for a High subject, and this difference is significant. Or, High subjects reduce their truth-telling rate by 34.5 points between DA-P2 and BOS-P2.

\footnotetext{
${ }^{25}$ We do not observe ceiling effects, something that might be a concern given that we use the Standard version of Raven progressive matrices.

${ }^{26}$ Spearman's rho $=.037, \mathrm{P}-\mathrm{val}=.61$.
} 
TABLE 6: DIFFERENCES IN STRATEGIES

\begin{tabular}{|c|c|c|c|c|c|c|}
\hline & & Truth & $\mathrm{SN}$ & STT & STM & Other \\
\hline \multirow{4}{*}{ High vs Low } & DA-P1 & $\begin{array}{c}.063 \\
(.072)\end{array}$ & $\begin{array}{l}-.059 \\
(.046)\end{array}$ & $\begin{array}{l}-.005 \\
(.015)\end{array}$ & $\begin{array}{c}.029 \\
(.017)\end{array}$ & $\begin{array}{l}-.028 \\
(.026)\end{array}$ \\
\hline & BOS-P1 & $\begin{array}{l}-.188 \\
(.039)\end{array}$ & $\begin{array}{l}-.071 \\
(.036)\end{array}$ & $\begin{array}{c}.057 \\
(.045)\end{array}$ & $\begin{array}{c}.244 \\
(.041)\end{array}$ & $\begin{array}{l}-.043 \\
(.034)\end{array}$ \\
\hline & DA-P2 & $\begin{array}{c}.126 \\
(.048)\end{array}$ & $\begin{array}{l}-.032 \\
(.024)\end{array}$ & $\begin{array}{l}-.014 \\
(.025)\end{array}$ & $\begin{array}{c}-.040 \\
(.008)\end{array}$ & $\begin{array}{l}-.040 \\
(.014)\end{array}$ \\
\hline & BOS-P2 & $\begin{array}{l}-.171 \\
(.050)\end{array}$ & $\begin{array}{l}-.027 \\
(.031)\end{array}$ & $\begin{array}{c}.097 \\
(.040)\end{array}$ & $\begin{array}{c}.106 \\
(.026)\end{array}$ & $\begin{array}{l}-.006 \\
(.011)\end{array}$ \\
\hline \multirow{2}{*}{ BOS-P1 vs DA-P1 } & Low & $\begin{array}{c}-.104 \\
(.040)\end{array}$ & $\begin{array}{c}.015 \\
(.039)\end{array}$ & $\begin{array}{c}.035 \\
(.025)\end{array}$ & $\begin{array}{c}.046 \\
(.033)\end{array}$ & $\begin{array}{c}.007 \\
(.035)\end{array}$ \\
\hline & High & $\begin{array}{l}-.354 \\
(.057)\end{array}$ & $\begin{array}{c}.004 \\
(.031)\end{array}$ & $\begin{array}{c}.097 \\
(.030)\end{array}$ & $\begin{array}{c}.261 \\
(.039)\end{array}$ & $\begin{array}{l}-.007 \\
(.028)\end{array}$ \\
\hline \multirow{2}{*}{ BOS-P2 vs DA-P2 } & Low & $\begin{array}{l}-.049 \\
(.055)\end{array}$ & $\begin{array}{c}.059 \\
(.040)\end{array}$ & $\begin{array}{c}.049 \\
(.027)\end{array}$ & $\begin{array}{l}-.030 \\
(.010)\end{array}$ & $\begin{array}{l}-.029 \\
(.017)\end{array}$ \\
\hline & High & $\begin{array}{l}-.345 \\
(.058)\end{array}$ & $\begin{array}{c}.064 \\
(.026)\end{array}$ & $\begin{array}{c}.116 \\
(.043)\end{array}$ & $\begin{array}{c}.146 \\
(.027)\end{array}$ & $\begin{array}{c}.004 \\
(.017)\end{array}$ \\
\hline
\end{tabular}

Notes: each cell in the table can be interpreted as the estimated difference in the probability of using each strategy. Estimates come from a multinomial logit model. The top panel shows the difference between High and Low subjects within each treatment. The bottom panels show the difference between DA and BOS for Low and High subjects. Robust standard errors in parentheses. Bold indicates significance at the .05 level.

The only significant response of Low subjects to the treatment is a reduction of truthful reports when moving from DA to BOS. This reduction is larger for High subjects (35-34 versus 5-10 percent). In each environment, High subjects increase their use of the 'correct' strategies in BOS, while Low subjects don't. As a consequence, High subjects end up playing significantly more STM and less truth-telling and SN relative to Low subjects under BOS - P1, and significantly more STT and STM and less truth-telling under BOS-P2. They are also significantly more truth-telling under DA-P2.

Table 7 presents the same comparisons, though using non-parametric methods. Since we base the tests on one observation per session, the observations for Low and High subjects are matched, and we adopt the Wilkoxon signedrank (WSR) test. Despite the fact that the tests have relatively low power in this case, results are similar to those outlined before.

Result 3. Compared to High subjects, Low subjects are significantly more likely to 
TABle 7: Differences BetweEn High AND LOW

\begin{tabular}{lcccccccccr}
\hline Treatment & \multicolumn{2}{c}{ Truthful } & \multicolumn{2}{c}{ SN } & \multicolumn{2}{c}{ STT } & \multicolumn{3}{c}{ STM } & \multicolumn{2}{c}{ Exp. Payoff } \\
& Z & P-val & Z & P-val & Z & P-val & Z & P-val & Z & P-val \\
\hline DA-P1 & 0.84 & .40 & -1.36 & .17 & -0.31 & .75 & 1.26 & .21 & 0.94 & .35 \\
BOS-P1 & -1.78 & .07 & -1.15 & .25 & 1.15 & .25 & $\mathbf{2 . 2 0}$ & .03 & $\mathbf{2 . 2 0}$ & $\mathbf{. 0 3}$ \\
& & & & & & & & & & \\
DA-P2 & $\mathbf{2 . 2 0}$ & .03 & -1.36 & .17 & -0.31 & .75 & $\mathbf{- 2 . 2 0}$ & $\mathbf{. 0 3}$ & 1.78 & .07 \\
BOS-P2 & -1.78 & .07 & -1.36 & .17 & $\mathbf{1 . 9 9}$ & $\mathbf{. 0 4}$ & $\mathbf{1 . 9 9}$ & $\mathbf{. 0 4}$ & $\mathbf{2 . 2 0}$ & $\mathbf{. 0 3}$ \\
\hline
\end{tabular}

Notes: the table reports, for each of the listed variables, the Wilkoxon signed-rank test, and the corresponding P-value, on the difference between High and Low subjects within each treatment. A positive statistic means a higher value for High subjects. The statistic is computed using one observation per session. Expected payoff is computed using a recombinant strategies procedure with 1000 recombinations for each subject in each period, and an identical number of tie breakers. Bold indicates significance at the .05 level.

report truthfully in BOS. They are significantly less likely to use STM in BOS-P1, STM and STT in BOS-P2.

Result 3 is in line with Hypotheses 3. Low subjects do not simply suffer from a truth-telling bias. Indeed, they also manipulate too often when they should report truthfully, as in DA-P2, while in BOS-P1 they appear overcautious. Low subjects seem to have a particularly hard time manipulating their second listed school. This is arguably due to the higher strategic complexity of this operation relative to manipulating the first listed school. For the latter, reasoning on capacities and others' first listed schools can be sufficient. In order to manipulate the second listed school, one also needs to simulate the first round of the mechanism and its consequences on available seats.

Average payoffs for all treatments are shown in Figure 5. Low and High subjects earn similar amounts under DA, while High subjects outperform Low ones under BOS. Since these payoffs depend on a number of random factors, we test for differences between Low and High subjects using the expected payoffs obtained through the recombinant strategies technique. A WSR test finds High subjects earn significantly more than Low ones in BOS and not in DA, under both preference environments (Table 7). ${ }^{27}$

Models (3) and (6) in Table 5 also investigate differences between Low and High subjects, respectively in P1 and P2. The corresponding marginal effects for the interaction between mechanism and cognitive ability are reported in the top panels of Figure 6. The difference in the expected payoff of Low and

\footnotetext{
${ }^{27}$ Figures 9 and 10 in Appendix $C$ report the average payoff of each strategy for each subject type.
} 

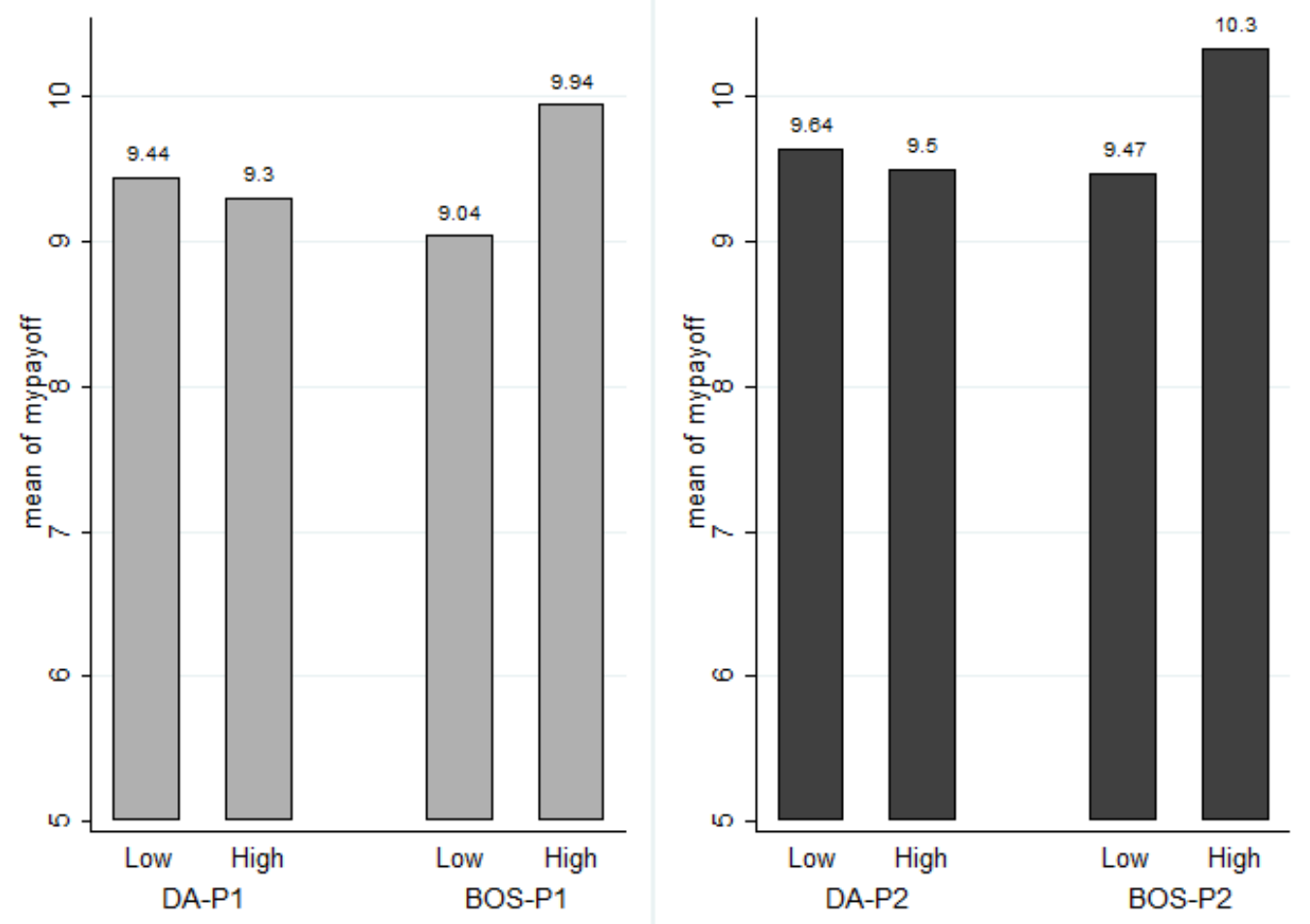

Notes: average payoffs computed for top (High) and bottom (Low) half of the distribution of Raven scores.

High subjects increases in BOS relative to DA, and High subjects earn significantly higher expected payoffs than Low ones in BOS, under both preference environments. In DA-P1 Low and High subjects have similar expected payoffs. In P2 High subjects outperform Low ones also in DA. Similarly, the bottom panels of Figure 6 show the linear relation between Raven score and predicted expected payoff for each treatment. They are obtained from models similar to (3) and (6), except they estimate the interaction between the mechanism and the (continuous) Raven scores, rather than the dummy High/Low. ${ }^{28}$ The predicted expected payoff increases more steeply with the Raven score under BOS. Indeed the marginal effect of one more Raven point - i.e., the slope of the depicted lines - is significantly different from zero only under BOS in both preference environments.

Overall, we show BOS induce larger inequalities between Low and High subjects. DA tends to equalize their payoffs. ${ }^{29}$ Thus, our results are in line with

\footnotetext{
${ }^{28}$ See the full estimates in Appendix C

${ }^{29}$ In model (6), but not in the other estimates, we find Low subjects earn less than High ones also in DA-P2. On top of being statistically less robust as a result, one could argue that
} 

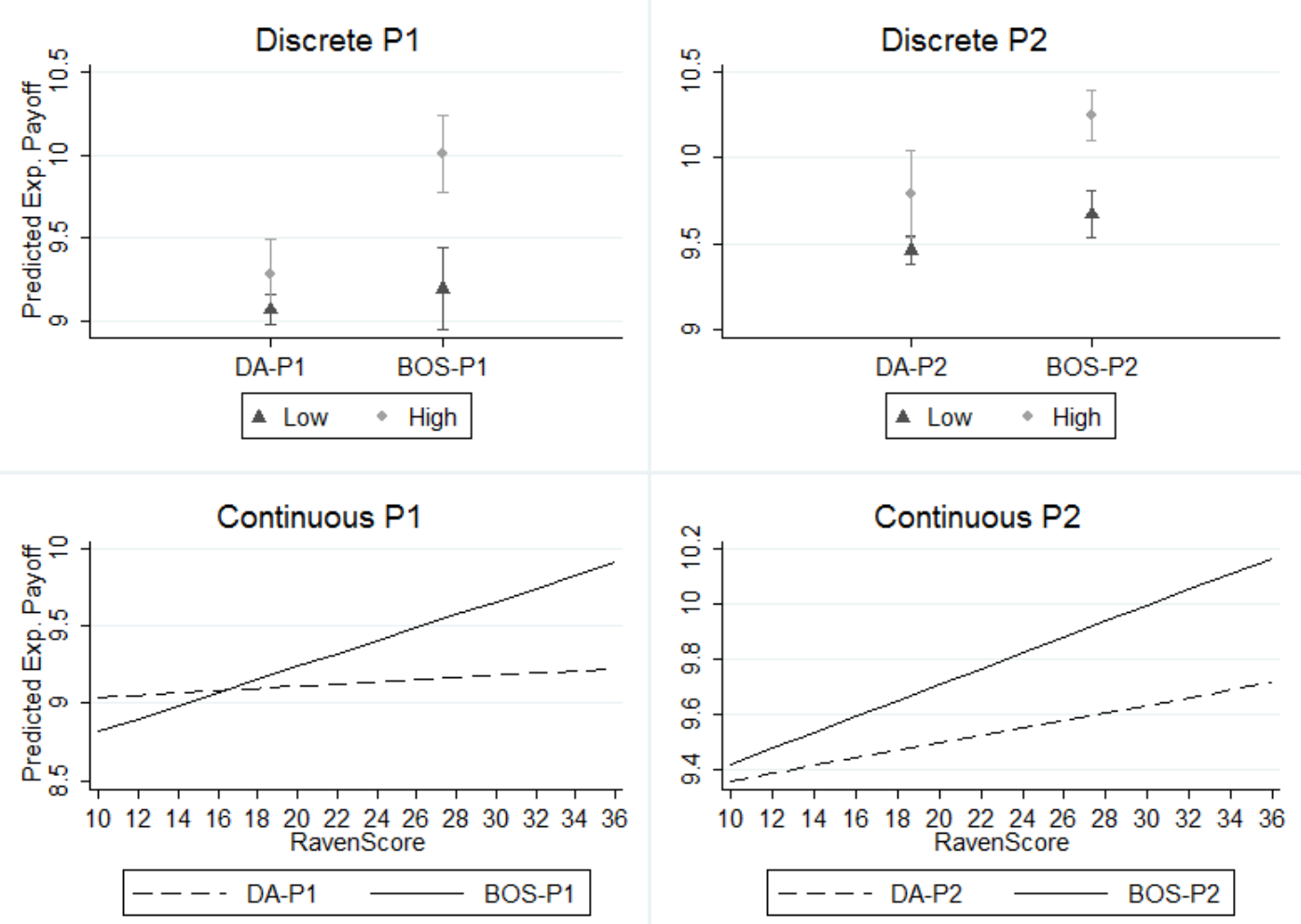

Notes: average payoffs computed for top (High) and bottom (Low) half of the distribution of Raven scores.

Hypothesis 4, and strongly support the leveling-the-playing-field hypothesis.

Result 4. High subjects earn higher payoffs than Low ones under BOS. Payoff differences are reduced under DA.

Table 8 shows how many High and Low subjects one is expected to find at each school. We use the allocations obtained from the recombinant strategies procedure to retrieve the average number of High subjects admitted at each school. ${ }^{30}$ If the strategies did not differ across groups, all cells should be equal to two. Spreads from this value are small under DA. Ability segregation emerges under BOS. In particular, Low subjects are under-represented at school $\mathrm{C}$ and over-represented at school D. In BOS-P1 there are 45 percent more High subjects in school C, and 30 percent more in school A, with respect to school D. In BOS-P2 there are 33 percent more High subjects in school C,

strategy-induced inequalities are easy to fix under DA, where straightforward advice can be given to parents.

${ }^{30}$ While our classification procedure does not guarantee this, in the experiment there were exactly the same number of High and Low subjects in each treatment. 
TABLE 8: NuMBER OF HIGH SUBJECTS PER SCHOOL

\begin{tabular}{lcccc}
\hline & DA-P1 & BOS-P1 & DA-P2 & BOS-P2 \\
\hline School A & 2.11 & 2.11 & 2.09 & 1.92 \\
School B & 1.97 & 1.91 & 2.00 & 2.05 \\
School C & 1.91 & 2.37 & 1.94 & 2.29 \\
School D & 2.01 & 1.63 & 1.95 & 1.72 \\
\hline
\end{tabular}

Notes: the table shows the expected average number of High subjects admitted at each school, given the strategies, in case axactly half of the subjects were High. The average is computed using a recombinant strategies procedure with 1000 recombinations for each subject in each period, and an identical number of tie breakers. The average is weighted to account for the different proportions of High subjects in different treatments.

and 20 percent more in school B, with respect to school D. ${ }^{31}$

Table 9 reports the difference in the probability that High and Low subjects have of being admitted at each school, and the corresponding tests of significance, based on the marginal effects obtained from a multinomial logit model. We find no significant differences between High and Low subjects in the probability of being assigned at any school under DA-P1 and DA-P2. When moving from DA to BOS, Low subjects become significantly more likely to be assigned to School D (second and third panel), and are significantly more likely to be admitted there than High subjects (first panel).

Result 5. Low subjects are over-represented at school $D$ and under-represented at school C under BOS.

Thus, BOS induce segregation by ability, confirming Hypothesis 5.

\section{Conclusions}

School choice is a politically sensitive issue. Because education distributes opportunities, fairness and equality concerns play a central role, and it is of paramount importance to identify the winners and losers that changes to the allocation mechanism can make. Our contribution helps achieving this in-

\footnotetext{
${ }^{31}$ Under DA and BOS-P1, High subjects are over-represented in school A. Since Low subjects use safe strategies more often when these are suboptimal, they end up under-represented at their preferred school. The 'safe bias' is found to be a major source of losses in empirical studies [Calsamiglia et al., 2015; He, 2014]. In the experiment it is the main departure from truth-telling under DA, and the main suboptimal strategy other than truth-telling under BOS, used around one in six cases when it should not be played in equilibrium.
} 
TABLE 9: DIFFERENCES IN PROBABILITY OF ASSIGNMENT AT EACH SCHOOL

\begin{tabular}{|c|c|c|c|c|c|}
\hline & & School A & School B & School C & School D \\
\hline \multirow{4}{*}{ High vs Low } & DA-P1 & $\begin{array}{c}.006 \\
(.055)\end{array}$ & $\begin{array}{l}-.001 \\
(.056)\end{array}$ & $\begin{array}{l}-.036 \\
(.036)\end{array}$ & $\begin{array}{c}.030 \\
(.016)\end{array}$ \\
\hline & BOS-P1 & $\begin{array}{c}.001 \\
(.042)\end{array}$ & $\begin{array}{l}-.011 \\
(.046)\end{array}$ & $\begin{array}{c}.102 \\
(.032)\end{array}$ & $\begin{array}{l}-.091 \\
(.042)\end{array}$ \\
\hline & DA-P2 & $\begin{array}{l}-.027 \\
(.046)\end{array}$ & $\begin{array}{l}-.003 \\
(.058)\end{array}$ & $\begin{array}{c}.020 \\
(.048)\end{array}$ & $\begin{array}{c}.009 \\
(.032)\end{array}$ \\
\hline & BOS-P2 & $\begin{array}{l}-.006 \\
(.028)\end{array}$ & $\begin{array}{c}.011 \\
(.046)\end{array}$ & $\begin{array}{c}.076 \\
(.048)\end{array}$ & $\begin{array}{l}-.080 \\
(.021)\end{array}$ \\
\hline \multirow{2}{*}{ BOS-P1 vs DA-P1 } & Low & $\begin{array}{c}.006 \\
(.034)\end{array}$ & $\begin{array}{c}.005 \\
(.040)\end{array}$ & $\begin{array}{l}-.077 \\
(0.24)\end{array}$ & $\begin{array}{c}.066 \\
(.022)\end{array}$ \\
\hline & High & $\begin{array}{c}.001 \\
(.036)\end{array}$ & $\begin{array}{l}-.005 \\
(.021)\end{array}$ & $\begin{array}{c}.060 \\
(.025)\end{array}$ & $\begin{array}{l}-.056 \\
(.024)\end{array}$ \\
\hline \multirow{2}{*}{ BOS-P2 vs DA-P2 } & Low & $\begin{array}{c}-.008 \\
(.028)\end{array}$ & $\begin{array}{c}-.002 \\
(.039)\end{array}$ & $\begin{array}{l}-.031 \\
(.031)\end{array}$ & $\begin{array}{c}.041 \\
(.019)\end{array}$ \\
\hline & High & $\begin{array}{c}.011 \\
(.027)\end{array}$ & $\begin{array}{c}.012 \\
(.034)\end{array}$ & $\begin{array}{c}.025 \\
(.038)\end{array}$ & $\begin{array}{c}-.048 \\
(.022)\end{array}$ \\
\hline
\end{tabular}

Notes: each cell in the table can be interpreted as the estimated difference in the probability of being admitted at each school. Estimates come from a multinomial logit model. The top panel shows the difference between High and Low subjects within each treatment. The bottom panels show the difference between DA and BOS for Low and High subjects. Robust standard errors in parentheses. Bold indicates significance at the .05 level.

formation, and assessing to which extent does Deferred Acceptance level the playing field.

We show that students of lower cognitive ability are worse off with respect to high ability ones under the Boston mechanism, because they fail to manipulate appropriately. This results in ability segregation under the Boston mechanism. Despite the fact that such segregation can emerge only due to different strategic behaviors, and not, as it is the case in most field context, to priority criteria or to correlation between preferences and ability, schools other than the worst admit up to 45 percent more participants of high cognitive ability relative to the worst school. While our game does not explicitly include peer-effects, one should keep them in mind in interpreting this result. The quality of a school is determined to a significant extent by the quality of its students [e.g, Henderson et al., 1978], and if worse schools are filled with students of low cognitive ability this would further decrease their performance 
[see also Calsamiglia et al., 2015; Cantillon, 2013], and depress the educational prospects of the already disadvantaged.

While these results support the choice of strategy-proof mechanisms, we also show Boston achieve higher ex-ante efficiency over Deferred Acceptance. Despite participants, including high ability ones, are not perfect strategizers, every school admits more students that value it relatively more under Boston. Thus, overall, our results highlight an important tradeoff between equality and efficiency in the choice between school allocation mechanisms. They also pave the way to future investigations of methods that try to resolve this tradeoff, either through the choice of appropriate alternative mechanisms, or by reducing the strategic ability gap between applicants. For instance, building on the experiment presented here, Basteck and Mantovani [2016] show that providing feedback on past demands improve the strategic performance of both Low and High subjects, but reduces the gap between the two only marginally.

\section{References}

AbdulkadiroĞLu, A., Y.-K. Che And Y. Yasuda, "Resolving Conflicting Preferences in School Choice: The" Boston Mechanism" Reconsidered," The American Economic Review 101 (2011), 399-410.

AbdulkadiroĞlu, A., P. A. Pathak, A. E. Roth and T. Sönmez, "The Boston public school match," American Economic Review (2005), 368-371.

AbDulKadiroĞLU, A. AND T. SÖnMEZ, "School choice: A mechanism design approach," The American Economic Review 93 (2003), 729-747.

BAsteCK, C. AND M. MANTOVAnI, "Protecting unsophisticated applicants in school choice through information disclosure," UNU-WIDER paper 2016/65 (2016).

Burks, S. V., J. P. CARpenter, L. Goette And A. Rustichini, “Cognitive skills affect economic preferences, strategic behavior, and job attachment," Proceedings of the National Academy of Sciences 106 (2009), 7745-7750.

CAlsamiglia, C. AND M. GÜEll, "The illusion of school choice: Empirical evidence from Barcelona," CEPR Discussion Paper No. DP10011 (2014).

Calsamiglia, C., G. Haeringer and F. Klijn, “Constrained school choice: An experimental study," The American Economic Review (2010), 1860-1874. 
Calsamiglia, C., F. Martínez-Mora, A. Miralles et Al., "School Choice Mechanisms, Peer Effects and Sorting," Univ. of Leicester Dept. Ecoomics WP No 15/01 (2015).

CANTILlON, E., "Preference Formation in School Choice," mimeo (2013).

CARPenter, P. A., M. A. Just AND P. Shell, “What one intelligence test measures: a theoretical account of the processing in the Raven Progressive Matrices Test.," Psychological review 97 (1990), 404.

Charness, G., A. Rustichini And J. VAn DE Ven, "Self-confidence and strategic deterrence," Tinbergen Institute Discussion Paper (2011).

Chen, Y., M. Jiang, O. Kesten, S. Robin And M. Zhu, "Matching in the Large: An Experimental Study," (2015).

CHEN, Y. AND O. KESTEN, "From Boston to Shanghai to deferred acceptance: Theory and experiments on a family of school choice mechanisms," in Auctions, Market Mechanisms, and Their Applications (Springer, 2012), 58-59.

CHEn, Y. AND T. SÖNMEZ, "School choice: an experimental study," Journal of Economic theory 127 (2006), 202-231.

CRosetto, P. AND A. Filippin, “The $\ddot{i}_{i} \frac{1}{2}$ bombï $i \frac{1}{2}$ risk elicitation task," Journal of Risk and Uncertainty 47 (2013), 31-65.

ERGIN, H. AND T. SÖNMEZ, "Games of school choice under the Boston mechanism," Journal of public Economics 90 (2006), 215-237.

Featherstone, C. And M. Niederle, "Improving on Strategy-proof School Choice Mechanisms: An Experimental Investigation," mimeo (2014).

FISCHBACHER, U., "z-Tree: Zurich toolbox for ready-made economic experiments," Experimental Economics 10 (2007), 171-178.

GILL, D. AND V. L. Prowse, “Cognitive Ability and Learning to Play Equilibrium: A Level-k Analysis," Journal of Political Economy forthcoming (2015).

GRAY, J. R. AND P. M. THOMPSON, "Neurobiology of intelligence: science and ethics," Nature Reviews Neuroscience 5 (2004), 471-482.

HE, Y., "Gaming the Boston School Choice Mechanism in Beijing," TSE Working Paper N 551 (2014).

Henderson, V., P. MieszKowski And Y. Sauvageau, "Peer group effects and educational production functions," Journal of Public Economics 10 (1978), 97-106. 
Klijn, F., J. PAIS AND M. VORSATZ, "Preference intensities and risk aversion in school choice: A laboratory experiment," Experimental Economics 16 (2013), 1-22.

LYNN, R. AND P. IRWING, "Sex differences on the progressive matrices: A metaanalysis," Intelligence 32 (2004), 481-498.

Miralles, A., "School choice: The case for the Boston mechanism," in Auctions, Market Mechanisms and Their Applications (Springer, 2009), 58-60.

PAIS, J. AND Á. PINTÉR, "School choice and information: An experimental study on matching mechanisms," Games and Economic Behavior 64 (2008), 303-328.

PATHAK, P. A. AND T. SÖNMEZ, "Leveling the playing field: Sincere and sophisticated players in the Boston mechanism," The American Economic Review 98 (2008), 1636-1652.

Plomin, R., “Genetics and general cognitive ability,” Nature 402 (1999), C25-C29.

Roth, A. E. AND M. A. O. SOTOMAYOR, Two-sided matching: A study in game-theoretic modeling and analysis, 18 (Cambridge University Press, 1992).

\section{A Equilibria}

Equilibria BOS-P1. We will show that in Preference Environment 1, there is an essentially unique equilibrium where 11 students report $A \succ_{i} C \succ_{i} B, D$ and 5 report $B \succ_{i} C \succ_{i} A$, D. We begin by showing that this profile is an equilibrium.

Consider students of type 1,3 and 4 who initially apply at $A$. They are admitted at $A$ with probability $4 / 11$ and rejected with probability $7 / 11$. If rejected, their conditional probability of acceptance at $C$ is between $4 / 7$ and $4 / 8$ : there are 7 applicants who were rejected at $A$ (and have the same conditional probability of acceptance at $C$ ) and another applicant who was rejected in a less competitive lottery at B (and therefore has a lower conditional probability of acceptance at $\mathrm{C}$ ). The corresponding expected payoffs for type 1,3 and 4 are bounded from below by $9.18,8.36$ and 7.73 , respectively.

If a student of type 1,3 or 4 deviates and applies at B in the first round, she should again rank $C$ second, as $A$ will be filled in round 1 . She is rejected at $B$ with probability $2 / 6$. In this case, she will compete with at least 7 other applicants at $C$ in the second round, so that the expected payoffs for type 1,3 and 4 when submitting $B \succ_{i} C \succ_{i} A, D$ are bounded from above by $7.66,8$ and 
7.66, respectively. ${ }^{32}$ If she applies at C or D directly in the first round, she will be accepted and her payoff will be even lower. Hence, there is no profitable deviation for types 1, 3 and 4.

A student of type 2 applying at $B$ is admitted with probability $4 / 5$. Hence, her expected payoff is higher than $4 / 5 \mathrm{p}(2, \mathrm{~B})=13.6$. Deviating and applying at $A$ in the first round would yield less than $4 / 12 p(2, A)+8 / 12 p(2, C)=9.33$ while applying at $C$ (or even $D$ ) in the first round yields at most $p(2, C)=6$.

A student of type 3 or 4 applying at $B$ receives an expected payoff higher than $4 / 5 p(3, B)=8$, since there is a positive probability that she will be admitted to $C$. Deviating and applying at $A$ yields an expected payoff of at most $4 / 12(p(3, A)+p(3, C)+p(3, D))=8$. Similarly, deviating and applying at $C$ in the first round yields $p(4, C)<p(3, C)=8$. Hence, there is no profitable deviation.

This establishes the strategy profile as equilibrium. Next, we show that no other (pure strategy) equilibrium exists. For that, let us denote the number of applicants at $A, B$ and $C$ in the first round as $\# A$, $\# B$ and $\# C$, respectively.

Claim 1. In any equilibrium, $\# A, \# B \geqslant 4$.

Proof of Claim: Assume $\# A<4$ or $\# B<4$. Then some type could switch and apply at her most preferred school and secure her highest possible payoff. $\diamond$

Claim 2. In any equilibrium, \#A $\geqslant \# B$.

Proof of Claim: Towards a contradiction assume \#A $<$ \#B. Then, any type 1, 3 or 4 initially applying at $B$ would switch and apply at $A$ instead. Hence, in equilibrium, $\# B \leqslant 4$, so that $\# A<4$, in contradiction to Claim 1.

Claim 3. In any equilibrium, types 1, 2, an 4 apply at A or B in the first round.

Proof of Claim: Assume otherwise, i.e. consider a type 1, 2 or 4 who applies at $C$. She will be admitted to $C$ or $D$, as $A$ and $B$ are filled in the first round. Hence, her payoff is at most $p(1, C)=p(2, C)=p(4, C)=6$. If $\# A \leqslant 9$, then a switch to $A$ yields an expected payoff no lower than $\frac{4}{9+1} p(4, A)=6.4$. If on the other hand $\# B \leqslant 5$, a switch to $B$ yields at least $\frac{4}{5+1} p(4, B)=6.66$. Hence we have $\# A=10, \# B=6-$ and no type 1, 2 or 4 applying at $C$.

Claim 4. In any equilibrium, types 3 apply at A or B in the first round.

\footnotetext{
${ }^{32}$ Since in the first round she was rejected in the less competitive lottery at $\mathrm{B}$, her conditional probability of acceptance at $C$ is strictly less than $4 / 8$ but in order to check that there is no profitable deviation, taking $4 / 8$ as an upper bound suffices.
} 
Proof of Claim: Assume otherwise, i.e. consider a type 3 who applies at C. Since no type 1,2 or 4 applies at $C$, she is accepted and receives $p(3, C)=8$. If $\# A \leqslant 7$, a switch to $A \succ_{i} C \succ_{i} B$, D yields an expected payoff of more than $\frac{4}{7+1} p(3, A)=8$, as she would be accepted at $C$ with positive probability. If $\# B \leqslant 4$, a switch to $B \succ_{i} C \succ_{i} A$, D yields an expected payoff of more than than $\frac{4}{4+1} p(3, B)=8$, as she would be accepted at $C$ with positive probability. Hence, we have $\# A \geqslant 8$, $\# B \geqslant 5$, so that $\# C \leqslant 3$.

If $\# A=8$, a switch to $A \succ_{i} C \succ_{i} B, D$ leaves at least two available seats at $C$ in round 2 and hence yields at least $\frac{4}{8+1} p(3, A)+\frac{5}{9} \frac{2}{6} p(3, C)=8.59$. Hence, we have $\# A \geqslant 9$, \#B $\geqslant 5$, so that $\# C \leqslant 2$.

If $\# A=9$, a switch to $A \succ_{i} C \succ_{i} B, D$ leaves at least three available seats at $C$ in round 2 and hence yields at least $\frac{4}{9+1} p(3, A)+\frac{6}{10} \frac{3}{7} p(3, C)=8.46$. Hence, we have $\# A \geqslant 10, \# B \geqslant 5$, so that $\# C \leqslant 1$.

Finally, if $\# A=10$, a switch to $A \succ_{i} C \succ_{i} B, D$ leaves four available seats at $C$ in round 2 and hence yields at least $\frac{4}{10+1} p(3, A)+\frac{7}{11} \frac{4}{8} p(3, C)=8.36$. Hence, we have $\# A \geqslant 11, \# B \geqslant 5$, so that $\# C=0$.

Since $C$ is available in round 2 by Claim 3 and 4 , while $A$ and $B$ are full, we know that everyone submits either $A \succ_{i} C \succ_{i} B, D$ or $B \succ_{i} C \succ_{i} A$, D. It remains to quantify and identify the applicants at each school.

Claim 5. In any equilibrium, $\# \mathrm{~A} \leqslant 11, \# \mathrm{~B} \geqslant 5$

Proof of Claim: Towards a contradiction assume $\# A=12, \# B=4$. Any type 3 applying at $A$ would deviate and apply $B$, as we saw when we established our candidate profile with $\# A=11, \# B=5$ as an equilibrium. Any type 2 applying at $A$ has an even higher incentive to deviate and apply at $B$.

Claim 6. In any equilibrium, $\# \mathrm{~A} \geqslant 11, \# \mathrm{~B} \leqslant 5$

Proof of Claim: Towards a contradiction assume $\# A \leqslant 10, \# B \geqslant 6$. Any type 1,3 or 4 applying at $B$ would deviate and apply at $A$, as we saw when we established our candidate profile with $\# A=11, \# B=5$ as an equilibrium.

Finally, observe that no type 1 applies at $B$ in equilibrium where they would receive at most $\frac{4}{5} p(1, B)+\frac{1}{5} \frac{1}{8} p(4, C)=8.6$ while a switch to $A$ would yield at least $\frac{4}{12} p(1, A)+\frac{8}{12} \frac{4}{8} p(1, C)=8.66$. Similarly, no type 2 applies at $A$ where she would receive at most $\frac{4}{11} p(2, A)+\frac{7}{11} \frac{4}{7} p(2, C)=8$ while a switch to $B$ would yield more than $\frac{4}{6} p(2, B)=11.33$. This concludes the characterization of equilibria in BOS-P1. 
Naive and strategic players in BOS-P1. We show that in the presence of naive, truthtelling players, the remaining strategic, best responding players will all submit either $A \succ_{i} C \succ_{i} B, D$ or $B \succ_{i} C \succ_{i} A, D-$ as they would in any pure Nash equilibrium. Moreover, the presence of naive players increases the incentives for strategic players to initially apply at the most competitive school relative to equilibrium. With sufficiently many naives, this yields $\# A=12$ and $\# B=4$ (the strategic players of type 2 continue to apply at B). Hence strategic players will all use skip-the-middle strategies.

First, observe that any $\# A, \# B \geqslant 4$ as naives always apply at their true first choice initially and strategic players would switch and apply there as well if it was underdemanded.

Next, observe that $\# A \geqslant \# B$ as there are more naives who prefer $A$ and strategic players of type 1,3,4 would switch to $A$ if $\# A<\# B$.

Also, all players will initially apply at either A or B: For naive players this is by assumption; for strategic players the reasoning behind the proofs of Claim 3 and 4 goes through unchanged.

Finally, note that naive players will rank either B or A second - neither of which is available in round two - while strategic players rank $C$ second, as in any equilibrium. What remains to be quantified is the number of strategic players who apply at $A$ and $B$ in round one.

Given any number of opponents initially applying at $A$ and $B$, a strategic player comparing the expected payoff from $A \succ_{i} C \succ_{i} B, D$ and $B \succ_{i} C \succ_{i} A, D$ finds that the presence of naive players increases her chance of being admitted at $C$ should they be rejected at their reported first choice. Moreover, in all relevant cases (i.e. where \#A $\geqslant \# B$ ), the increase in payoff on $A \succ_{i} C \succ_{i} B, D$ is weakly larger since the probability of being rejected at $A$ in round one is higher. Thus, the presence of naives increases strategic players' incentives to apply at $A$ so that compared to equilibrium we find $\# A \geqslant 11$ and $\# B \leqslant 5$.

It is easily verified that all stratgic players of type 2 will then submit $B \succ_{i}$ $\mathrm{C} \succ_{i} A, D$. Moreover with two naive players of each type, one finds that all strategic players of types 1, 3 and 4 submit $A \succ_{i} C \succ_{i} B, D$ (see Basteck and Mantovani [2016] for a the characterization of pseudo-equilibria in BOS-P1 and BOS-P2 when half of the population of each type is naive).

Equilibria BOS-P2. We claim that strategy profiles where all type 1 and three of type 4 report $A \succ_{i} B, C, D$, all type 2 and one of type 4 report $B \succ_{i} A, C, D$ and all type 3 report $C \succ_{i} A, B, D$ are the only pure strategy equilibria.

First, to check that the profile constitutes an equilibrium, consider students 
of type 1 and 4 who apply at $A$ in the first round. They are admitted at $A$ with probability $4 / 7$. If they are rejected at $A$, they are admitted at D. For a student of type 1 or 4 , this corresponds to an expected payoff of at least 9.14. Deviating and applying at $B$ in the first round yields 7.33; applying at $C$ yields 5.6. Hence, there is no profitable deviation.

A student of type 2 or 4 applying at B is admitted with probability $4 / 5$ and otherwise ends up at D. Hence, her expected payoff is at least 8.8. Deviating and applying at $A$ in the first round yields 8; applying at $C$ yields 5.6.

Students of type 3 apply at $C$, are admitted and receive $p(3, C)=11$. If all others rank $C$ second, deviating and applying at $A$ yields at most $\frac{1}{2} \cdot p(3, A)+$ $\frac{1}{2} \frac{1}{4} \cdot p(3, C)=9.38$; applying at $B$ yields at most $4 / 6 \cdot p(3, B)+\frac{2}{6} \frac{1}{5} \cdot(3, C)=8.1$. Thus there is no profitable deviation if sufficiently many students rank $C$ second.

Next, we show that there are no other equilibrium profiles.

Claim 1. In any equilibrium, $\# A \geqslant 4$.

Proof of Claim: Assume \#A $<4$. Any type could switch and apply at $A$, to be accepted with probability one and secure her most preferred school.

Claim 2. In any equilibrium, $\# \mathrm{~B} \geqslant 4$.

Proof of Claim: Assume otherwise. Then any student could switch to B and secure an expected payoff of 15 or 11 respectively. Since no one is willing to do this, we know that the sum over expected payoffs must be at least 4 . $15+12 \cdot 11=192$. But the highest possible sum over deterministic payoffs is $4 \cdot 20+4 \cdot 15+4 \cdot 11=184-$ a contradiction.

Claim 3. In any equilibrium, $\# A \geqslant \# B$.

Proof of Claim: Assume otherwise, i.e. \#A < \#B in equilibrium. Then any type 1, 3 or 4 who applies at $B$ in the first round would switch and apply at $A$ instead. Hence, as we are in equilibrium, there can be no type 1, 3 or 4 applying at $B$. Then $\# B \leqslant 4$, so that $\# A<4$, in contradiction to Claim 1 .

Claim 4. In any equilibrium, types 1, 2, an 4 apply at A or B in the first round.

Proof of Claim: Assume otherwise, i.e. consider a type 1, 2 or 4 who applies at C. She will be admitted to $C$ or $D$, as $A$ and $B$ are filled in the first round. Hence, her payoff is at most $p(1, C)=p(2, C)=p(4, C)=7$. If $\# A \leqslant 8$ a switch to $A$ yields an expected payoff no lower than $\frac{4}{8+1} p(4, A) \approx 7.11$. If on the other hand $\# B \leqslant 5$ a switch to $B$ yields at least $\frac{4}{5+1} p(4, B) \approx 7.33$. Then the only situation were some type 1,2 or 4 applies at $C$ would have $\# A=9$, $\# B=6$ and $\# C=1$. 
In such an equilibrium, everybody would apply at $\mathrm{C}$ in the second round. But then, a type 3 applying at $A$ would receive at most $\frac{4}{9} 16+\frac{5}{9} \frac{3}{5} 11 \approx 10.77$ while a type 3 applying at $B$ is admitted at $D$ with positive probability and hence receives less than 11 . In both cases, she would deviate and apply at $C$ where she receives $p(3, C)=11$ for sure.

Claim 5. In any equilibrium, no students of type 3 apply at B in the first round.

Proof of Claim: Assume otherwise, so that $\# \mathrm{C}<4$. If $\# \mathrm{~B}>4$, everyone ranks $C$ second and no type 3 is willing to apply at $B$ instead of $C$ as she risks being assigned to D. Hence (by Claim 2) $\# B=4$. But then, some type 2 applies at $A$ where $\# A \geqslant 9$ and receives at most 11 , while applying at $B$ yields at least $12 . \diamond$

Claim 6. In any equilibrium, all students of type 3 apply at $\mathrm{C}$ in the first round.

Proof of Claim: Assume otherwise, so that $\# \mathrm{C}<4$. Then in the second round, there are available seats at $C$ but not at $A$ or $B$. Hence, every student that applies at $A$ will rank $C$ second. Moreover, if $\# B>4$, every student applying at $B$ will also rank $C$ second.

If $\# C=3$ there is one available seat at $C$ in round two and $\# A \geqslant 7$; a student of type 3 who initially applies at $A$, receives less than $\frac{4}{7} \cdot 16+\frac{3}{7} \frac{1}{3} \cdot 11 \approx 10.71$ and would prefer to apply at $C$ to receive $p(3, C)=11$ for sure.

If $\# C=2$ there are two remaining seats at $C$ in round two. If $\# A=\# B=7$, a type 3 initially applying at $A$ receives at most $\frac{4}{7} \cdot 16+\frac{3}{7} \frac{2}{6} \cdot 11 \approx 10.71$. If on the other hand $\# A \geqslant 8$, she is admitted at $A$ with probability of at most $\frac{1}{2}$ and admitted at $D$ with probability of at least $\frac{1}{4}=\mathbb{P}\left(l_{i} \geqslant 13\right)$. Hence her expected payoff is at most 10.75 . In either case, she would deviate and apply at $C$.

If $\# C<2$ then $\# A \geqslant 8$. Hence, as we just saw, no student of type 3 would initially apply at $A$ but rather deviate and apply at $C$.

Claim 7. In any equilibrium, at least 7 students apply at $\mathrm{A}$ in the first round.

Proof of Claim: By Claim 3, 4 and $6, \# A \geqslant 6 \geqslant \#$. Towards a contradiction, assume $\# A=6=\# B$. Then some type 1 or 4 applies at $B$ and receives $\frac{4}{6} \cdot 11 \approx$ 7.33. A switch to $A$ would yield at least $\frac{4}{7} \cdot 16 \approx 9.14$.

Claim 8. In any equilibrium, 7 students apply at $\mathrm{A}$ in the first round.

Proof of Claim: By Claim 7, \#A $\geqslant 7$. Towards a contradiction, assume $\# A \geqslant 8$ so that $\# B=4$. Then some type 2 or 4 applies at $A$, and receives at most $\frac{4}{8} 16=8$. A switch to $B$ would yield at least $\frac{4}{5} \cdot 11=8.8$. 
To summarize, we now know that $\# A=7$, $\# B=5$ and $\# C=4$. It remains to show that all type 1 apply at $A$ and all type 2 apply at $B$. Towards a contradiction, assume there is a type 1 who applies at $B$. There she receives $\frac{4}{5} \cdot 11=8.8$ If she deviates and applies at $A$, she would receive $\frac{4}{8} 20=10$. Similarly, a type 2 applying at $A$ would receive $\frac{4}{7} 16 \approx 9.1$ while deviating and applying at $B$ yield $\frac{4}{6} 15=10$. This concludes the characterization of equilibria in BOS-P2.

Naive and strategic players in BOS-P2. First note, that since everyone's favourite school is $A$, we have $\# A \geqslant 4$. We claim that if at least 4 of the 8 players of type 2 and 4 are strategic, B will also be filled in round 1 . Assume otherwise, i.e. $\# \mathrm{~B}<4$. With $A$ filled in round one, all but the following four strategies are dominated: $\mathrm{A} \succ_{i} \mathrm{~B} \succ_{i} \ldots, \mathrm{A} \succ_{i} \mathrm{C} \succ_{i} \ldots, \mathrm{B} \succ_{i} \mathrm{C} \succ_{i} \ldots$ and $\mathrm{C} \succ_{i} \mathrm{~B} \succ_{i} \ldots$ The last strategy may only be played by students of type 3 - all others prefer to apply at $B$ initially to earn either 15 or 11 .

Then $\# A \geqslant 9$ and $A$ admits - in expected terms - at most $\frac{4}{9} \cdot 4$ students of type 1 , so that the average expected payoff is at most

$$
\frac{1}{16}\left(\frac{4}{9} \cdot 4 \cdot 20+\frac{5}{9} \cdot 4 \cdot 16+4 \cdot 15+4 \cdot 11\right)=10.944 .
$$

Hence, a strategic student of type 4 will not submit $A \succ_{i} B \succ_{i} \ldots$. her expected payoff would have to be weakly higher than 11 (she could get into $B$ for sure) and this payoff would also be the minimum expected payoff for the naive applicants, contradicting an average expected payoff of 10.944. Similarly, strategic players of type 2 will not submit $A \succ_{i} B \succ_{i} \ldots$ - this would require their payoff from this strategy to be at least 15 and hence every naive player's payoff from this strategy to be higher than 11.

Finally, if $\# A=9$ we have $\# C>3$ so that neither types 2 or 4 would submit $A \succ_{i} C \succ_{i} \ldots$ as it would earn them $\frac{4}{9} \cdot 16<11$. If $\# A \geqslant 10$ the payoff is at most $\frac{4}{10} \cdot 16+\frac{6}{10} \cdot 7<11$. Hence, all strategic players of type 2 and 4 would apply at $\mathrm{B}$ initially contradicting \# $<4$.

\section{B Experimental materials}

\section{Instructions}

Welcome to this experiment in decision-making. You will receive 5 Euros as a show-up fee. Please, read carefully these instructions. The amount of money you earn depends on the decisions you and other participants make. In this 
experiment, on top of the show-up fee, you can earn between 0 and 26.30 Euro. In the experiment you will earn ECU (Experimental Currency Units). At the end of the experiment we will convert the ECU you have earned into Euro according to the rate: $1 \mathrm{ECU}=0.7 \mathrm{EURO}$. You will be paid your earnings privately and confidentially after the experiment. Throughout the experiment you are not allowed to communicate with other participants in any way. If you have a question please raise your hand. One of us will come to your desk to answer it.

\section{TASK 1}

On the sheet of paper on your desk you see a puzzle: a matrix with 8 graphic elements and an empty slot. There are eight possible numbered elements that could fill the empty slot. Only one is correct. Your task is to identify the element that correctly solves the puzzle. You choose the element you want by typing the corresponding number and pressing $\mathrm{OK}$.

You will face 36 such puzzles, divided in three blocks of 12 puzzles each. Within each block, you can move back and forth through puzzles even without solving them, and change the answers you have given before. You have five minutes to complete blocks 1 and 2, and eight minutes to complete block 3. For each puzzle you correctly solve you earn $0.1 \mathrm{ECU}$. You will be informed about your score and earnings at the end of the experiment.

\section{TASK 2}

On the sheet of paper on your desk you see a field composed of 100 numbered boxes. You earn $0.1 \mathrm{ECU}$ for every box that is collected. Every second a box is collected, starting from the top-left corner. Once collected, the box disappears from the screen and your earnings are updated accordingly. At any moment you can see the amount earned up to that point.

Such earnings are only potential, however, because behind one of these boxes hides a time bomb that destroys everything that has been collected.

You do not know where this time bomb lies. You only know that the time bomb can be in any place with equal probability: the computer will randomly determine the number of the box containing the time bomb. Moreover, even if you collect the time bomb, you will not know it until the end of the experiment.

Your task is to choose when to stop the collecting process. You do so by hitting 'Stop' at any time. 


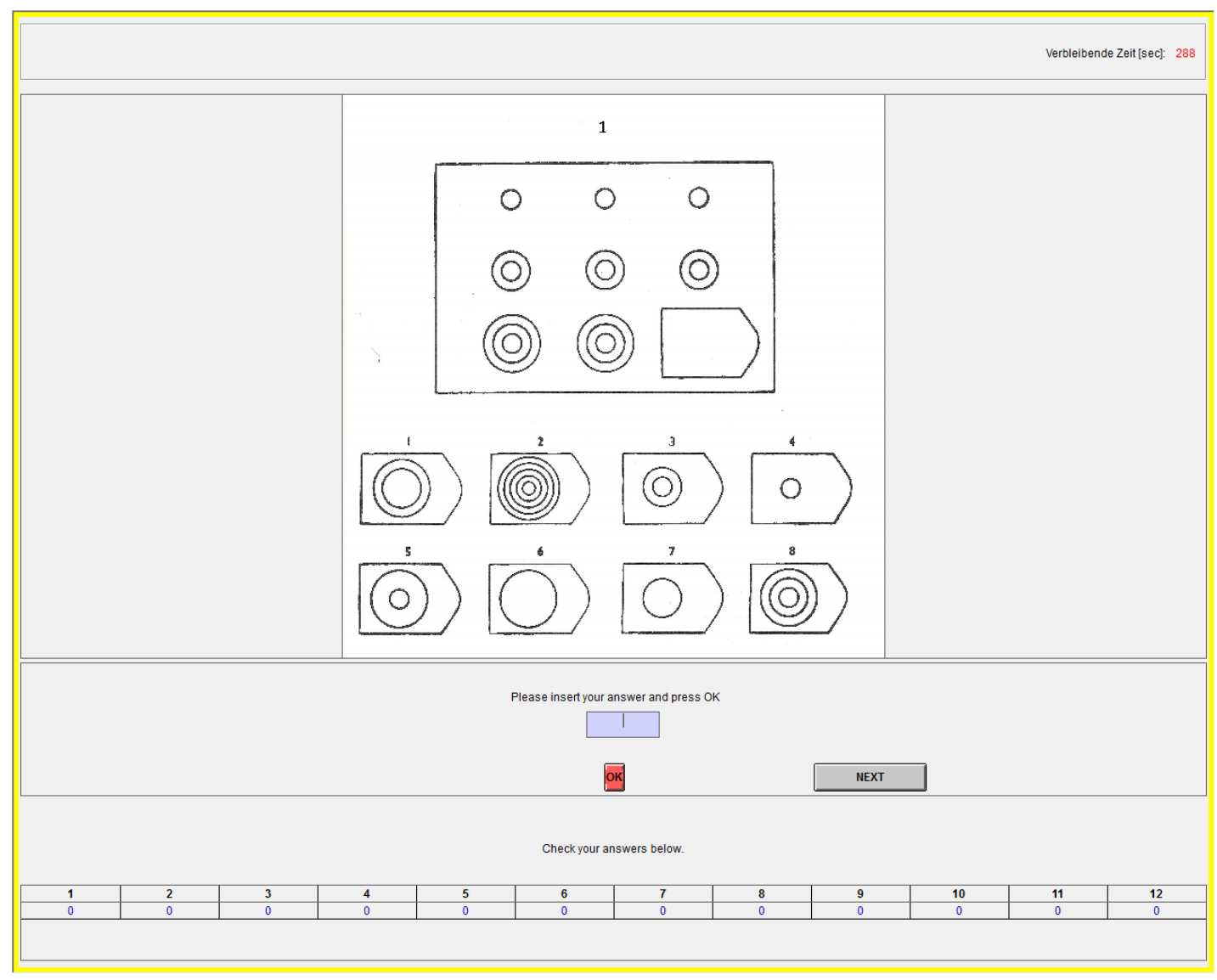

If you happen to have collected the box where the time bomb is located, you will earn zero. If the time bomb is located in a box that you did not collect you will earn the amount of money accumulated when hitting 'Stop'. We will start with a practice round. After that, the paying experiment starts.

\section{TASK 3}

In this part of the experiment, we model a procedure to allocate seats at schools to students. Each student has to submit an application form to apply for a seat at a school. You and the other participants take the role of students. An assignment procedure that we will explain in detail below, decides, based on the application forms submitted by you and the other 15 participants, who receives a seat at which school.

There are 10 Rounds, in which you will apply anew for a seat at a school. All rounds are independent: where you are admitted, depends only on the application forms submitted in this round. Your chances in the current round 


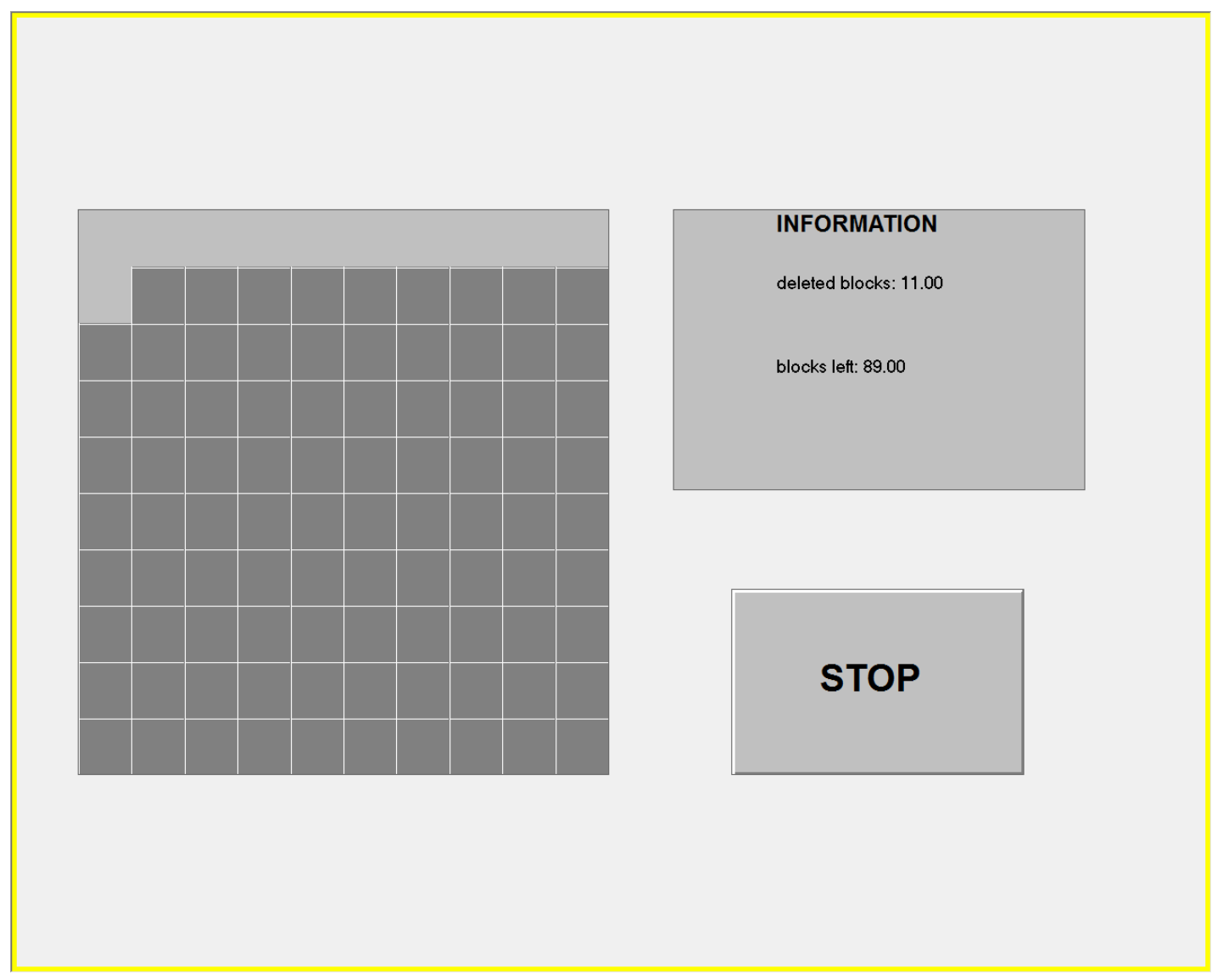

are not influenced by your own decisions or the decisions of other participants in previous rounds. At the end of the experiment, one round is selected randomly. Your payoff for Task 3 depends on the school that you have been admitted to in that round.

\section{Earnings: rounds 1-5}

In each round, you and the remaining 15 participants apply for one of 16 seats. These are distributed over 4 schools - A, B, C, D - where each school has 4 seats. The earnings of a student admitted at a school depends on his type. There are 4 types of students - 1, 2, 3, 4 - with 4 students of each type. The type of a participant will be randomly drawn in each round. The earnings of a student, depending on his type and the school the he is admitted to, are summarized in the table below.

You can read the table as follows: in a round where you are a student of type 2 and are admitted at school $\mathrm{C}$ you earn $6 \mathrm{ECU}$ - if this round is chosen to be paid out, this amount will be converted to Euros and paid out at the end of the experiment. In the same way, a student of type 3 that is admitted at school 


\begin{tabular}{lcccc}
\hline ECU for a seat at school & A & B & C & D \\
\hline Type 1 & 20 & 10 & 6 & 0 \\
Type 2 & 16 & 17 & 6 & 0 \\
Type 3 & 16 & 10 & 8 & 0 \\
Type 4 & 16 & 10 & 6 & 0 \\
\hline
\end{tabular}

A receives a payoff of $16 \mathrm{ECU}$.

The payoffs above remain unchanged for the first 5 rounds. In rounds 6-10, there is different payoffs table, which you will see on the screen.

\section{Available decisions}

In each round, you have to submit an application form. To do so, you have to fill in under 'first choice', 'second choice', 'third choice' and 'fourth choice' the name of the respective school: ' $\mathrm{A}^{\prime},{ }^{\prime} \mathrm{B}^{\prime},{ }^{\prime} \mathrm{C}^{\prime}$ or ${ }^{\prime} \mathrm{D}$ '. This ranking determines the order with which your applications are sent to the schools, and, through the procedure outlined below, the school you are assigned to. You are free to choose the order in which you rank schools. When you are done, confirm your list by clicking 'submit'.

\section{The assignment procedure [DA]}

Once all application forms have been submitted, each student draws a lottery number from 1 to 16: each number is drawn once. Each student has the same chances. For the assignment, students with a lower lottery number receive preferential treatment over students with a higher lottery number.

The assignment of participants to available seats works as follows:

phase 1:

- Application by students. Each student applies at the school that he ranked as first choice on his application form.

- Admission. If at most 4 students apply at a school, all of them are preliminarily accepted. If more students apply at a school than the school has seats, the school preliminarily accepts the 4 students with the lowest lottery number. Applicants that do not receive a seat are permanently rejected at the respective school.

phase 2:

- Application by students. Every student, who has been accepted preliminarily in round 1, still applies at the respective school. Every student that was rejected permanently in round 1, applies at the school that is next on his application form. 
- Admission. Each school preliminarily accepts the 4 applicants with the lowest lottery number. If there are less than 4 applicants, the school preliminarily accepts all applicants. Applicants that do not receive a seat are permanently rejected at the respective school.

phase 3:

- Application by students. Every student, who has been accepted preliminarily in round 2, still applies at the respective school. Every student that was rejected permanently in round 2, applies at the school that is next on his application form.

- Admission. Each school preliminarily accepts the 4 applicants with the lowest lottery number. If there are less than 4 applicants, the school preliminarily accepts all applicants. Applicants that do not receive a seat are permanently rejected at the respective school.

$(\ldots)$

The procedure continues according to these rules. The procedure ends, once a phase is reached where every applicant is preliminarily accepted. In this moment, preliminary acceptance becomes permanent acceptance.

After every round you are informed about your lottery number and about the school where you received a seat. Then, the next round starts.

\section{The assignment procedure [BOS]}

Once all application forms have been submitted, each student draws a lottery number from 1 to 16: each number is drawn once. Each student has the same chances. For the assignment, students with a lower lottery number receive preferential treatment over students with a higher lottery number.

The assignment of participants to available seats works as follows: phase 1:

- Application by students. Each student applies at the school that he ranked as first choice on his application form.

- Admission. If at most 4 students listed a school as first choice, all of them receive a seat at that school. If more students listed a school as first choice, than the school has seats, the seats at that school are given to the students with the lowest lottery numbers. Students, who receive a seat in phase 1 are admitted for good; for them, the assignment procedure is over. Applicants that do not receive a seat move to the next phase.

phase 2: 
- Application by students. Every student, who has not been assigned a seat in phase 1, applies at the school that he ranked as second choice on his application form.

- Admission. If in the second phase there are at most as many applicants as free seats at the school, all of them receive a seat at the school. If there are more applicants than free seats, the remaining free seats are given to the students with the lowest lottery numbers. If there are no free seats left, no applicant receives a seat at the school. Students, who receive a seat in phase 2 are admitted for good; for them, the assignment procedure is over. Applicants that do not receive a seat move to the next phase.

phase 3:

- Application by students. Every student, who has not been assigned a seat in phases 1 and 2, applies at the school that he ranked as third choice on his application form.

- Admission. If in the third phase, there are at most as many applicants as free seats at the school, everyone receives a seat at the school. If there are more applicants in the third phase than free seats, the remaining free seats are given to the students with the lowest lottery number. If there are no free seats left, no applicant receives a seat at the school. Students, who receive a seat in phase 3 are admitted for good; for them, the assignment procedure is over. Applicants that do not receive a seat move to the next phase.

phase 4:

- Application by students. Every student, who has not been assigned a seat in phases 1, 2 and 3, applies at the school that he ranked as fourth choice on his application form.

- Admission. Since there are 16 applicants and 16 seats, there are as many free seats in phase 4 as applicants. Everyone receives a seat.

After every round you are informed about your lottery number and about the school where you received a seat. Then the next round starts.

\section{Example [DA]}

To illustrate the procedure described above, we consider an example. In this example, there are 8 students and 4 schools $-\mathrm{V}, \mathrm{W}, \mathrm{X}, \mathrm{Y}-$ with 2 seats each to be assigned. Each Student draws a lottery number between 1 and 8 .

phase 1:

- Student number 1 applies at his first choice, school W. Since he is the only applicant there for two seats, he is preliminarily accepted. 


\begin{tabular}{cccccc}
\hline student & $\begin{array}{c}\text { Lottery } \\
\text { number }\end{array}$ & $\begin{array}{c}\text { First } \\
\text { choice }\end{array}$ & $\begin{array}{c}\text { Second } \\
\text { choice }\end{array}$ & $\begin{array}{c}\text { Third } \\
\text { choice }\end{array}$ & $\begin{array}{c}\text { Fourth } \\
\text { choice }\end{array}$ \\
\hline 1 & 7 & W & V & Y & X \\
2 & 5 & V & W & X & Y \\
3 & 2 & X & V & Y & W \\
4 & 8 & V & X & Y & W \\
5 & 1 & V & Y & W & X \\
6 & 3 & X & W & Y & V \\
7 & 6 & $\mathrm{X}$ & W & Y & V \\
8 & 4 & V & Y & X & W \\
\hline
\end{tabular}

- Students number 2, 4, 5 and 8 apply at school V, that has only two seats available. The students with the two lowest lottery numbers (Students number 5 and 8) are preliminarily accepted at school V. Students number 2 and 4 receive no seat in this phase.

- Students number 3, 6 and 7 apply at school X, that also has two available seats. Since there are more applicants than available seats, students with the lowest lottery numbers (student number 3 and 6) are preliminarily accepted at $X$. Student number 7 receives no seat in this phase.

- Students number 1, 3, 5, 6 and 8 have been preliminarily accepted. Students number 2, 4 and 7 have received no seat in this phase. The procedure moves to the next phase.

phase 2:

- Student number 2, 4 \& 7 have no seat yet and apply at their second choice.

- Students number 2 and 7 apply at school W. Together with student number 1 who was preliminarily accepted there, there are now three applicants for two available seats. The school preliminarily accepts the applicants with the lowest lottery number (students number 2 and 7 ). Student 1, receives no seat in this phase.

- Student number 4 applies at school $X$. There, there are now three applicants, students number 3, 4, and 6, and only two seats. The school preliminarily accepts students number 3 and 6 . Student number 4 receives no seat in this phase.

- Students number 1 and 4 have received no seat in this phase. The procedure moves to the next phase.

phase 3:

- Student number 1 applies at his second choice, school V. Together with the preliminarily accepted students number 5 and 8, there are now three appli- 
cants for two available seats. The school preliminarily accepts the applicants with the lowest lottery number, students number 5 and 8 . Student 1 receives no seat in this phase.

- Student number 4 has been rejected twice and now applies at his third choice, school Y. There he is the only applicant and he is preliminarily accepted.

- Students number 1 has received no seat in this phase. The procedure moves to the next phase.

phase 4:

- Student number 1 applies at his third choice, school Y. Together with the preliminarily accepted student number 4, there are now two applicants for two available seats. The school accepts both.

- All Students have a preliminary acceptance at the end of the phase. The procedure stops; preliminary acceptances become permanent acceptances.

We arrive at the following assignment:

\begin{tabular}{lcccccccc}
\hline Student number & 1 & 2 & 3 & 4 & 5 & 6 & 7 & 8 \\
\hline school & $\mathrm{Y}$ & $\mathrm{W}$ & $\mathrm{X}$ & $\mathrm{Y}$ & $\mathrm{V}$ & $\mathrm{X}$ & $\mathrm{W}$ & $\mathrm{V}$ \\
\hline
\end{tabular}

We start with a short quiz and an example. Then we begin with round 1.

\section{Example [BOS]}

To illustrate the procedure described above, we consider an example. In this example, there are 8 students and 4 schools $-\mathrm{V}, \mathrm{W}, \mathrm{X}, \mathrm{Y}$ - with 2 seats each to be assigned. Each Student draws a lottery number between 1 and 8 .

\begin{tabular}{cccccc}
\hline student & $\begin{array}{c}\text { Lottery } \\
\text { number }\end{array}$ & $\begin{array}{c}\text { First } \\
\text { choice }\end{array}$ & $\begin{array}{c}\text { Second } \\
\text { choice }\end{array}$ & $\begin{array}{c}\text { Third } \\
\text { choice }\end{array}$ & $\begin{array}{c}\text { Fourth } \\
\text { choice }\end{array}$ \\
\hline 1 & 7 & W & V & Y & X \\
2 & 5 & V & W & X & Y \\
3 & 2 & X & V & Y & W \\
4 & 8 & V & X & Y & W \\
5 & 1 & V & Y & W & X \\
6 & 3 & X & W & Y & V \\
7 & 6 & X & W & Y & V \\
8 & 4 & V & Y & X & W \\
\hline
\end{tabular}

phase 1:

- Student number 1 applies at his first choice, school W. Since he is the only applicant there for two seats, he is accepted. 
- Students number 2, 4, 5 and 8 apply at school V, that has only 2 seats available. The students with the two lowest lottery numbers (Student number 5 and 8) are accepted at school A. Students number 2 and 4 receive no seat in this phase.

- Students number 3, 6 and 7 apply at school X, that also has two available seats. Since there are more applicants than available seats, students with the lowest lottery numbers (students number 3 and 6) are accepted at $X$. Student number 7 receives no seat in this phase.

- The assignment procedure ends for students number $1,3,5,6$, and 8 , who all received a seat at a school. Students number 2,4 and 7 have received no seat in this phase and move to the next phase.

phase 2:

- Students number 2, 4 \& 7 have no seat yet and apply at their second choice.

- Students number 2 and 7 apply at school W, where there is one free seat available. This is assigned to the student with the lowest lottery number (student number 2).

- Student number 4 applies at school $\mathrm{X}$. There, there are no free seats.

- Students number 4 and 7 have received no seat in this phase and move to the next phase.

phase 3:

- Students number 4 and 7 apply at their third choice school, school Y, and are admitted, as school D has two free seats available. With this, the assignment procedure ends.

We arrive at the following assignment:

\begin{tabular}{lcccccccc}
\hline Student number & 1 & 2 & 3 & 4 & 5 & 6 & 7 & 8 \\
\hline school & W & W & X & Y & V & X & Y & V \\
\hline
\end{tabular}

We start with a short quiz and an example. Then we begin with round 1.

\section{Additional figures and results}

Figures 9 - 10 show the expected average payoff of each strategy for each student type in each treatment. Truthful reports pay the highest payoffs in DA. In BOS-P1 STM is the best strategy. Manipulation of the first listed school -i.e., the 'safe' strategies SN and STT - are instead rather taxing. In BOS-P2, STM 
Figure 9: AVERAGE PAYOFF OF EACH STRATEGY, BY PLAYER TYPE - P1

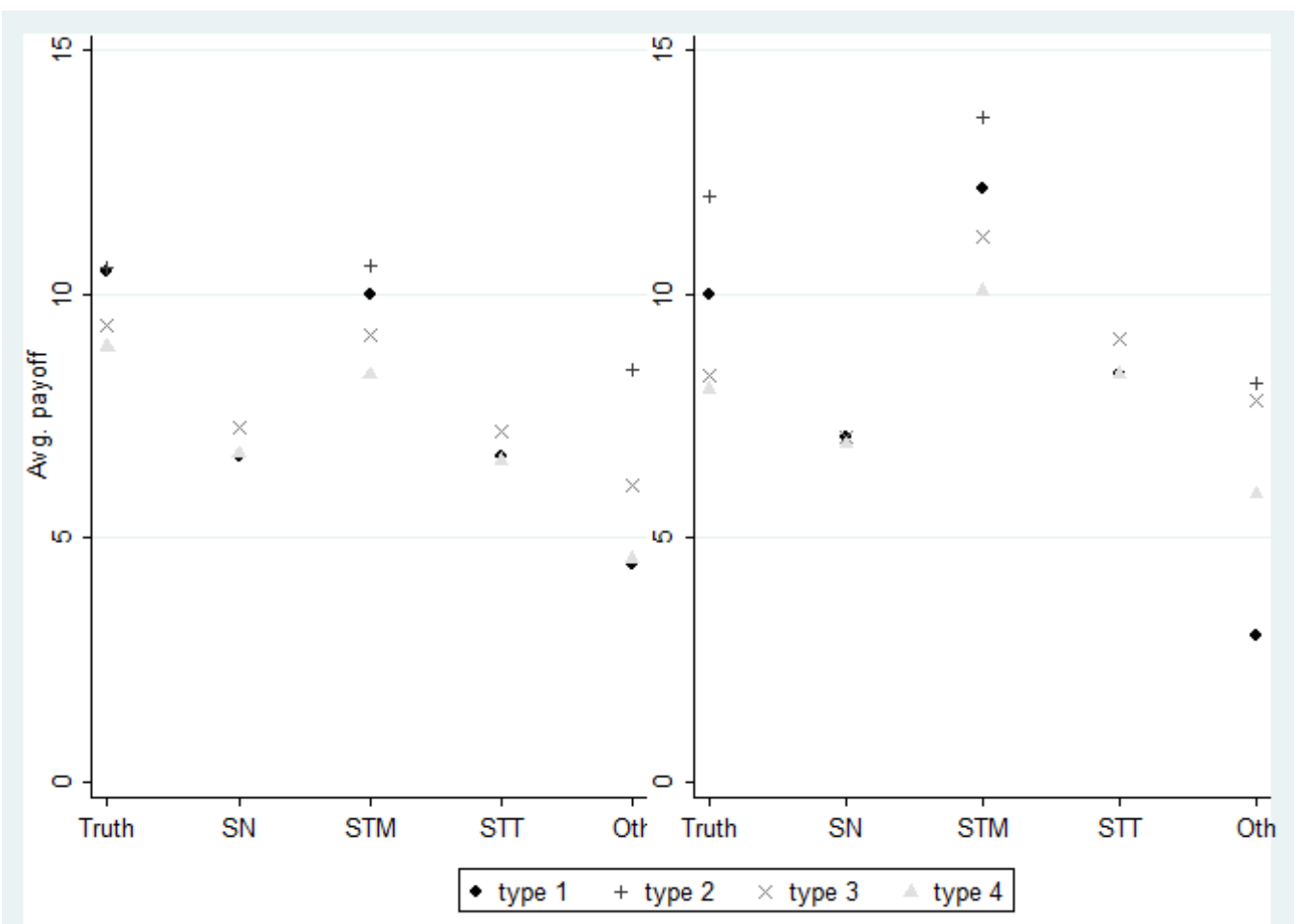

Figure 10: AVERAGE PAYOFF OF EACH STRATEGY, BY PLAYER TYPE - P2

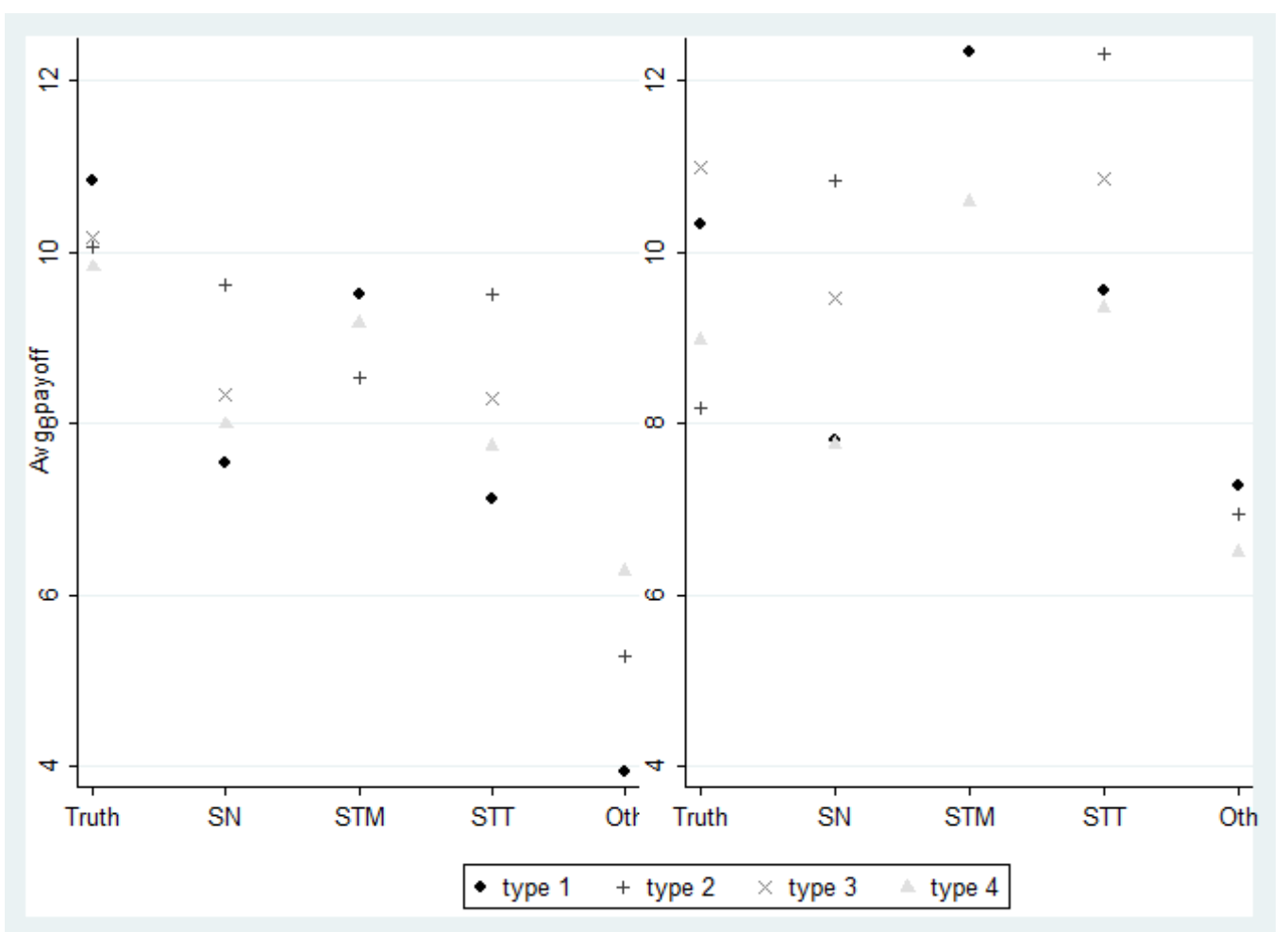



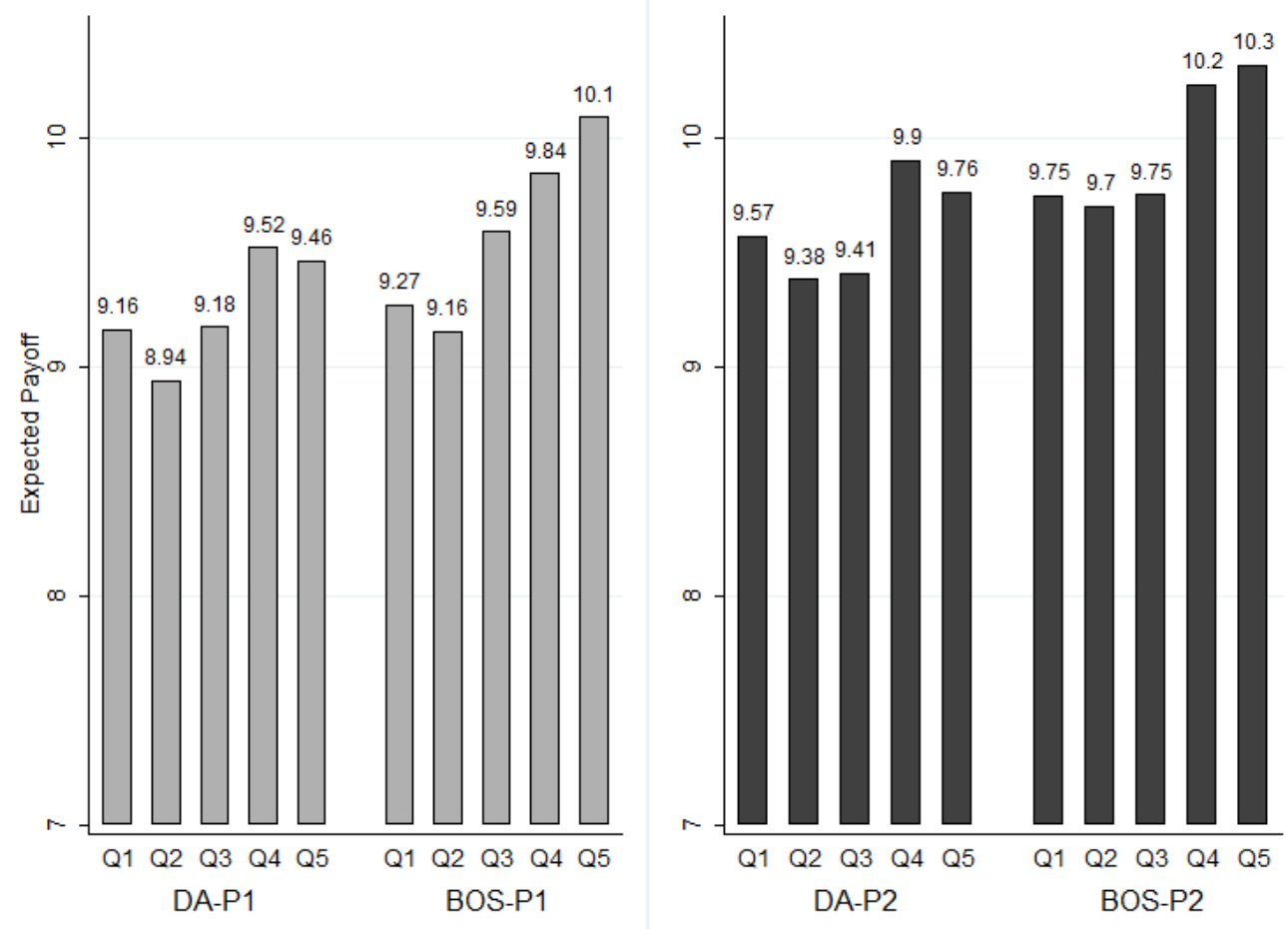

pays the highest payoffs for types 1 and 4, while STT is the best strategy for type 2, while type 3 is almost indifferent between STT and truthful reporting.

Section 2 provides detailed hypotheses on the strategies of students of different types. In particular we now how many applicants of each district we should observe at each school in the first round of the allocation process. Table 10 compares these prediction with actual data. On aggregate, comparative statics across treatments are always in the predicted direction: overall, there are more applicants at school $A$ under DA than under BOS. Students who are expected to list their true first choice most often do so. Subjects of type 3 and 4 tend to over-manipulate their first choice in P1, and in particular under Boston. Students of type 3 in BOS-P2 seems the furthest from the equilibrium prediction: they do not grab the full advantage of listing school $C$ first and are almost as likely to list, instead, school A and school B first. Similarly, too many students, in particular of type 4, apply at school B first in BOS-P1.

In the main text we have focused on the difference between High and Low subjects, where the threshold between the two is set at the median of the distribution of Raven scores. Table 11 reports regressions, where the dependent variable is the expected payoff as derived from the recombinant strategies technique. Instead of using the dummy classification into Low and High 


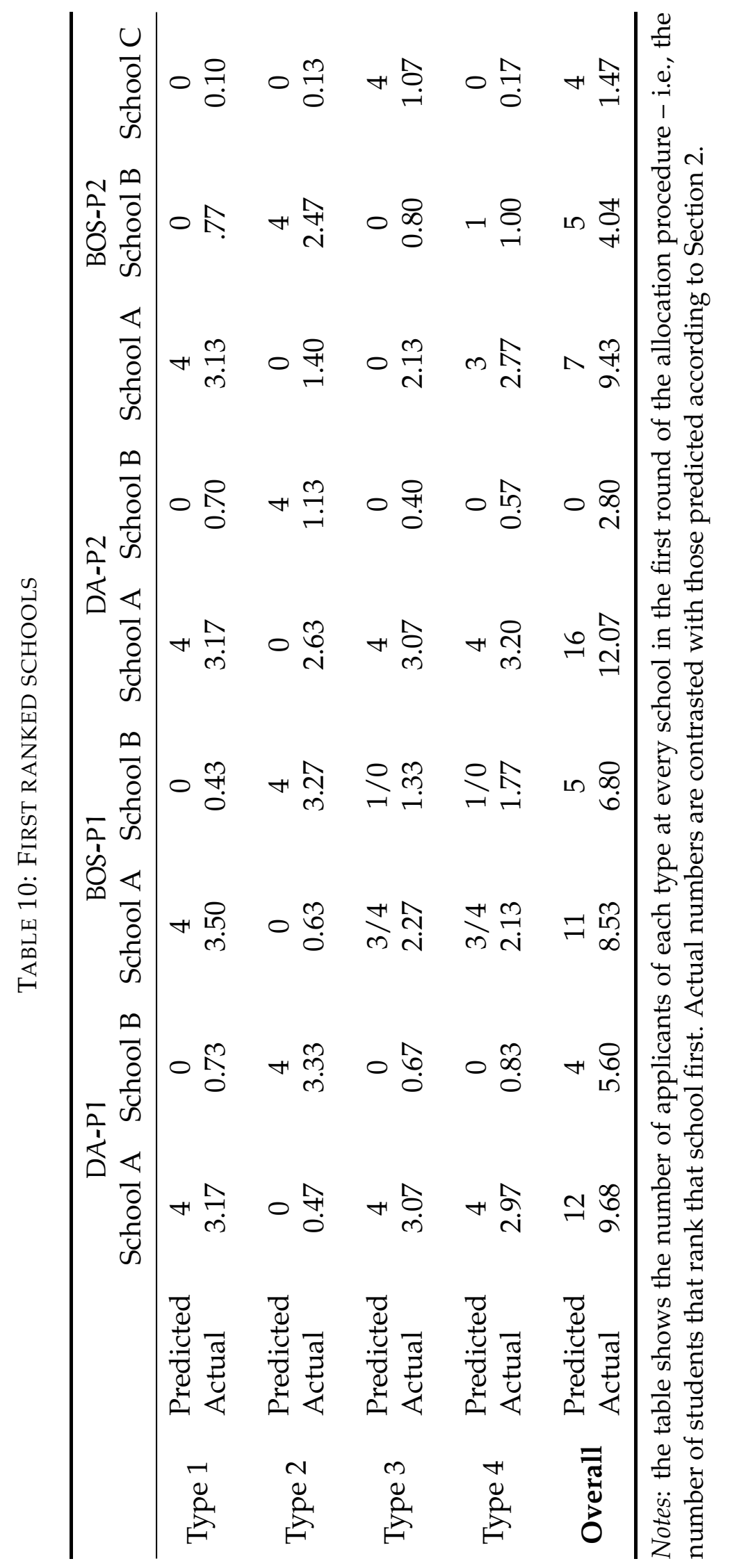




\begin{tabular}{|c|c|c|c|c|c|c|}
\hline & \multicolumn{6}{|c|}{ Dep. Var.: Expected payoff } \\
\hline & $(1)$ & $\begin{array}{l}\text { P1 } \\
(2)\end{array}$ & (3) & $(4)$ & $\begin{array}{c}\text { P2 } \\
(5)\end{array}$ & (6) \\
\hline BOS & $\begin{array}{c}0.416^{* * *} \\
(0.133)\end{array}$ & $\begin{array}{c}-0.560 \\
(0.679)\end{array}$ & $\begin{array}{l}-0.569 \\
(0.480)\end{array}$ & $\begin{array}{l}0.325^{* * *} \\
(0.0982)\end{array}$ & $\begin{array}{l}-0.539 \\
(0.714)\end{array}$ & $\begin{array}{c}-0.0898 \\
(0.569)\end{array}$ \\
\hline Raven & $\begin{array}{l}0.0281^{* *} \\
(0.0134)\end{array}$ & $\begin{array}{l}0.00715 \\
(0.0213)\end{array}$ & $\begin{array}{l}0.00716 \\
(0.0131)\end{array}$ & $\begin{array}{c}0.0225 \\
(0.0136)\end{array}$ & $\begin{array}{l}0.00400 \\
(0.0192)\end{array}$ & $\begin{array}{c}0.0136 \\
(0.0174)\end{array}$ \\
\hline BOS*Raven & & $\begin{array}{c}0.0335 \\
(0.0259)\end{array}$ & $\begin{array}{l}0.0348^{* *} \\
(0.0166)\end{array}$ & & $\begin{array}{c}0.0296 \\
(0.0245)\end{array}$ & $\begin{array}{c}0.0150 \\
(0.0208)\end{array}$ \\
\hline age & & & $\begin{array}{c}0.0166 \\
(0.0162)\end{array}$ & & & $\begin{array}{r}-0.00342 \\
(0.0193)\end{array}$ \\
\hline female & & & $\begin{array}{c}-0.478^{* * *} \\
(0.157)\end{array}$ & & & $\begin{array}{c}-0.0878 \\
(0.100)\end{array}$ \\
\hline period & & & $\begin{array}{c}0.0128 \\
(0.0335)\end{array}$ & & & $\begin{array}{c}0.0251 \\
(0.0305)\end{array}$ \\
\hline 2.mydistrict & & & $\begin{array}{c}1.122^{* * *} \\
(0.380)\end{array}$ & & & $\begin{array}{c}-0.201 \\
(0.266)\end{array}$ \\
\hline 3.mydistrict & & & $\begin{array}{c}-1.057^{* * *} \\
(0.114)\end{array}$ & & & $\begin{array}{l}0.0774 \\
(0.218)\end{array}$ \\
\hline 4.mydistrict & & & $\begin{array}{c}-1.714^{* * *} \\
(0.173)\end{array}$ & & & $\begin{array}{c}-1.027^{* * *} \\
(0.293)\end{array}$ \\
\hline order & & & $\begin{array}{l}0.170^{* * *} \\
(0.0573)\end{array}$ & & & $\begin{array}{l}-0.197 \\
(0.105)\end{array}$ \\
\hline choicebret & & & $\begin{array}{c}0.0151^{* *} \\
(0.00695)\end{array}$ & & & $\begin{array}{c}0.0103 \\
(0.00557)\end{array}$ \\
\hline _cons & $\begin{array}{c}8.363^{* * *} \\
(0.380)\end{array}$ & $\begin{array}{c}8.980^{* * *} \\
(0.596)\end{array}$ & $\begin{array}{c}8.363^{* * *} \\
(0.882)\end{array}$ & $\begin{array}{c}8.973^{* * *} \\
(0.395)\end{array}$ & $\begin{array}{c}9.519^{* * *} \\
(0.542)\end{array}$ & $\begin{array}{c}9.165^{* * *} \\
(0.744)\end{array}$ \\
\hline Obs. (groups) & $960(12)$ & $960(12)$ & $960(12)$ & $960(12)$ & $960(12)$ & $960(12)$ \\
\hline
\end{tabular}

Notes: the dependent variable is computed using recombinant strategies procedure with 1000 recombinations for each subject in each period, and an identical number of tie breakers. In parentheses we report robust standard errors, clustered at the session level. ${ }^{*},{ }^{* *},{ }^{* *}$ : statistically significant at the $10 \%, 5 \%$ and $1 \%$ level, respectively. 
FIGURE 12: EXPECTED PAYOFFS FOR MEN (M) AND WOMEN (W)
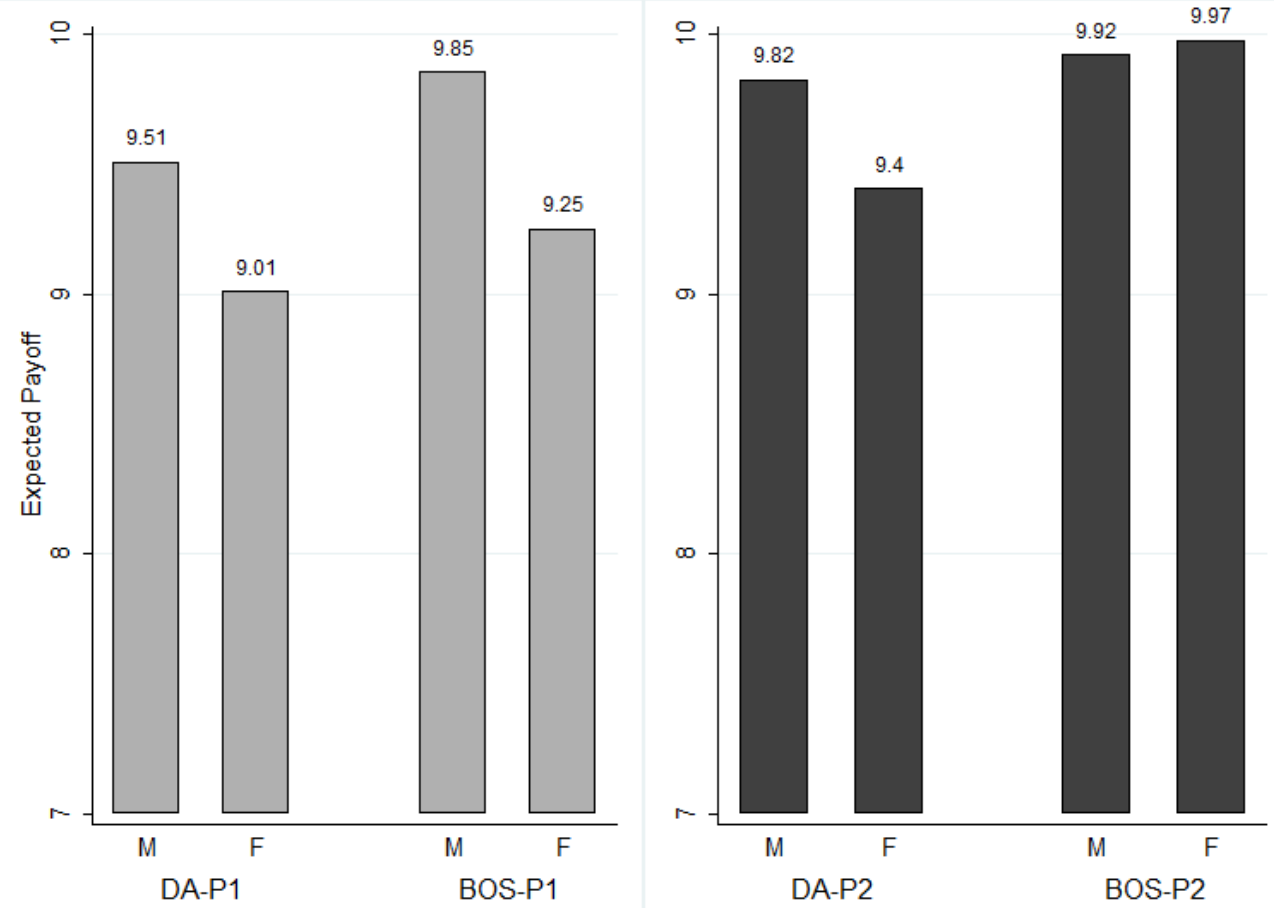

types, the Raven score is emplyed as a regressor. The marginal effects reported in Figure 6 are obtained from models (3) and (6). Figure 11 shows the expected payoffs within quintiles of the distribution of Raven scores. All figures are in line with our main results.

As reported in Table 5, women earn significantly less than men in both P1 and $\mathrm{P} 2$. Figure 12 shows that this difference appears in all treatments, except BOS-P2. Women represent 47 percent od our sample. In line with previous results [see the meta-analysis in Lynn and Irwing, 2004], they have significantly lower Raven scores (WRS test: $z=3.03, \mathrm{P}-\mathrm{val}<.01$ ). If anything, they are also more risk averse relative to men (WRS test: $z=1.93$, P-val $=.05$ ). However, the gender gap survives when we control for cognitive ability and risk preferences. ${ }^{33}$ We look at the strategies used by men and women in Table 12, with an approach similar to the one adopted in Table 6. Women tend to overmanipulate under DA. In particular, they use more STT (in P1) and 'Other' strategies (in P1 and P2). In the latter case, 72 percent of the times they list school C first. In BOS-P1, they use less STM and more SN strategies. These

\footnotetext{
${ }^{33}$ We note that our main results hold true for both men and women, when tested on the two groups separately. That is DA levels the playing field between High and Low, and BOS achieve higher average payoffs. Results are available upon request.
} 
TABLE 12: DIFFERENCES IN STRATEGIES

\begin{tabular}{llccccc}
\hline & & Truth & SN & STT & STM & Other \\
\hline & DA-P1 & $\mathbf{- . 0 7 7}$ & .038 & .005 & -.019 & $\mathbf{. 0 5 3}$ \\
& & $\mathbf{( . 0 3 7 )}$ & $(.038)$ & $(.012)$ & $(.022)$ & $\mathbf{( . 0 2 5 )}$ \\
F vs M & BOS-P1 & .095 & .090 & -.022 & $\mathbf{- . 1 4 7}$ & -.015 \\
& & $(.058)$ & $\mathbf{( . 0 4 1 )}$ & $(.039)$ & $\mathbf{( . 0 4 8 )}$ & $(.032)$ \\
& DA-P2 & $\mathbf{- . 1 2 4}$ & .044 & $\mathbf{. 0 4 0}$ & .009 & $\mathbf{. 0 3 1}$ \\
& & $\mathbf{( . 0 5 0 )}$ & $(.050)$ & $\mathbf{( . 0 1 3 )}$ & $(.014)$ & $\mathbf{( . 0 0 9 )}$ \\
& BOS-P2 & -.026 & .021 & .004 & -.015 & .015 \\
& $(.043)$ & $(.045)$ & $(.051)$ & $(.012)$ & $(.010)$ \\
\hline
\end{tabular}

Notes: each cell in the table can be interpreted as the estimated difference between women $(F)$ and men $(\mathrm{M})$ in the probability of using each strategy. Positive values indicate women use more of the corresponding strategy. Estimates come from a multinomial logit model. Robust standard errors in parentheses. Bold indicates significance at the .05 level.

results suggest that women play more cautiously than men over and beyond what our measure of risk preferences can capture. Indeed, in BOS-P2, where opting for a safe first choice can be optimal, the strategies of men and women are similar and they also earn similar expected payoffs. 